\title{
Regulation of EMT by STAT3 in gastrointestinal cancer (Review)
}

\author{
BO LI and CHEN HUANG \\ Department of General Surgery, Shanghai General Hospital, \\ Shanghai Jiao Tong University School of Medicine, Shanghai 200080, P.R. China \\ Received September 30, 2016; Accepted November 10, 2016
}

DOI: $10.3892 /$ ijo.2017.3846

\begin{abstract}
Gastrointestinal (GI) cancer is characterized by its aggressiveness and tendency to metastasize at early stage. Epithelial-mesenchymal transition (EMT), commonly known as the preparing step of metastasis, may account for the aggressive phenotype of GI cancer cells. The process of EMT is finely orchestrated by multiple layers of regulators. Signal transducer and activator of transcription 3 (STAT3) is a transcription factor constitutively activated in diverse malignancies. Recent studies have suggested an involvement of STAT3 in GI cancer EMT. In this review, we first take an insight into the oncogenic functions of STAT3 in GI cancer, and then summarize the possible mechanisms by which STAT3 regulates the EMT process. Through the extensive interactions with EMT-inducing transcription factors and noncoding RNAs, and crosstalk with other signaling pathways, STAT3 has been demonstrated to promote the mesenchymal and invasive phenotype of GI cancer, which provides rationales for specifically targeting STAT3 to prevent and reverse the progression of GI cancer.
\end{abstract}

\section{Contents}

1. Introduction

2. Molecular mechanism of EMT

3. Oncogenic role of STAT3 in GI cancer

4. Role of STAT3 in regulating EMT of GI cancer

5. Conclusion and outlook

\section{Introduction}

Gastrointestinal (GI) cancer, which refers to the malignancies of the GI tract and accessory organs of digestion,

Correspondence to: Dr Chen Huang, Department of General Surgery, Shanghai General Hospital, Shanghai Jiao Tong University School of Medicine, 100 Haining Road, Shanghai 200080, P.R. China E-mail: richard-hc@sohu.com

Key words: STAT3, gastrointestinal cancer, epithelial-mesenchymal transition represents the most common cancer and the leading cause of cancer-related death worldwide (1). According to the American Cancer Society, a total of 304,930 new GI cancer cases and an approximate deaths of 153,030 are estimated to occur during 2016 (2). In China, cancers of stomach, liver, esophagus and colorectum are among the 5 leading causes of cancer death (3). Most patients with GI cancer have advanced tumors with regional or distant metastasis upon presentation, which precludes them for radical resection. Among those who have received intentionally curable surgery, some still failed to survive due to the occult dissemination of cancer cells.

The epithelial-mesenchymal transition (EMT), first described by Elizabeth Hay in 1980s using a model of chick primitive streak formation, is integral in embryonic development, tissue repairing and also, occurs as an unintentional behavior of cells during fibrosis and cancer progression $(4,5)$. According to these distinct biological settings, EMT has been proposed to be categorized into three subtypes (6). The first, termed 'type 1', is associated with embryogenesis and organ development, such as gastrulation, neural crest formation and heart valve formation. The type 2 EMT, set in a context of trauma or inflammatory injury, is required for wound healing and tissue repairing. If the inflammation is persistent, however, this type of EMT also cause undesirable result-organ fibrosis. Different from these two types, the type 3 EMT, which exclusively occurs in neoplastic cells, is completely detrimental. In tumors of epithelial origin, immotile epithelial cells undergoing type 3 EMT are converted to mesenchymal-like cells with migratory ability (Fig. 1). By conferring cancer cells with capacity to invade, EMT drives the progression of indolent cancer in situ to an aggressive metastatic one (4-6). In addition, emerging evidence has shown that type 3 EMT also contributes to induction of cancer stem cells (CSCs), drug resistance and immune escape during GI cancer progression $(4,7,8)$.

Signal transducer and activator of transcription 3 (STAT3), which belongs to the STAT family, is in general transiently activated in normal cells but constitutively activated in a wide variety of blood malignancies and solid tumors, including breast cancer, prostate cancer, head and neck cancer, melanoma, brain cancer, as well as GI cancers (9-13). As one of the limited transcription factors that converge multiple oncogenic signaling pathways, STAT3 acts as the critical 'switch' and controls the expression program of tumor-associated genes, whereby STAT3 is extensively involved in biological processes of GI malignancies varying from cell cycle, apoptosis, angiogenesis, stemness, metastasis to immune evasion (9). 

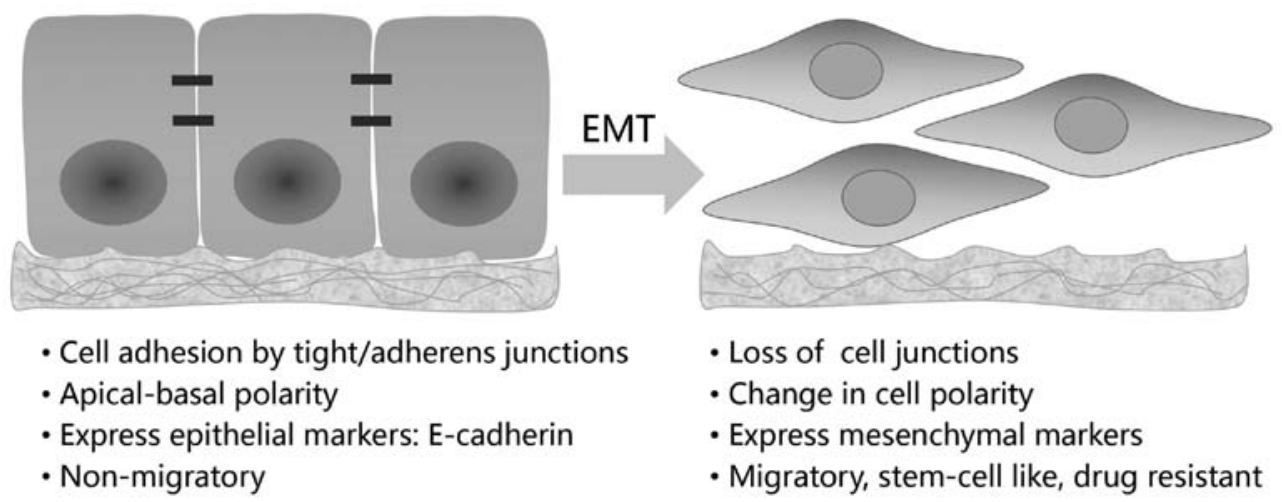

- Loss of cell junctions

- Change in cell polarity

- Express mesenchymal markers

- Migratory, stem-cell like, drug resistant

Figure 1. Cellular changes associated with type 3 EMT. In tumors of epithelial origin, epithelial cells undergoing type 3 EMT are converted into mesenchymal-like cells. This process is characterized by the loss or reduction of epithelial markers, in particular E-cadherin. More importantly, these converted cells acquire migratory abilities, which allow them to invade the basement membrane and further metastasize to distant organs.

In this review, we aim to discuss the molecular processes of STAT3-mediated EMT in GI cancer. We first describe the basic mechanisms that regulate the EMT process, then outlines the extensive oncogenic function of STAT3 in GI cancer, in particular its potential role in tumorigenesis, metastasis and generation of CSCs. Based on the theory that EMT is the early step of metastasis and is intimately associated with tumor stemness, we hypothesized that STAT3 may also exert an effect in EMT of GI cancer. Therefore, in the third section, we focus on the possible mechanisms by which STAT3 contributes to the initiation and resolution of EMT program. Through investigating into its interactions with specific transcription factors, miRNAs and signaling pathways, a critical role of STAT3 in GI cancer EMT has been fundamentally established, which makes STAT3 a candidate for preventing and reversing the EMT process in GI cancer.

\section{Molecular mechanism of EMT}

Hallmark of EMT is the loss of E-cadherin, a dominant constituent of the adhesion junctions (4-6,14). E-cadherin functions to maintain an intact cell-cell interaction and a stabilized cytoskeleton, thus preventing tumor cell mobility, invasion and subsequent dissemination. In GI cancer, reduced expression of E-cadherin is significantly correlated with poorly-differentiated phenotype, lymph node and distant organ metastasis $(15,16)$. Therefore, repression of this determinant molecule is considered to be a central event during EMT. As such, the EMT-transcription factors (EMT-TFs) are basically classified according to their direct or indirect repression on E-cadherin. The zinc-finger binding transcription factor Snaill was first discovered to downregulate E-cadherin gene expression by directly binding to its promoter in epithelial tumor cells (17). After the initial identification of the interaction between Snaill and CDH1 gene (which encodes E-cadherin), many other EMT-TFs such as Snail2 (also known as Slug), zinc finger E-box-binding homeobox 1 (ZEB1) and ZEB2 (also know as SIP1), the basic helix-loop-helix (bHLH) factor E47 (also known as TCF3), Krüppel-like factor 8 (KLF8) were successively discovered (4). While other factors, including Twist, fork-head box protein C2 (FOXC2), goosecoid and E2-2 (also known as TCF4), are demonstrated to induce EMT without direct binding to the promoter of CDH1 (4). Except for a dramatic change in E-cadherin expression, EMT is characterized by the reduction of other epithelial molecules such as claudins, occludin, zona occludens-1 (ZO-1) and cytokeratins, as well as the concomitant increase in mesenchymal markers, including vimentin, $\mathrm{N}$-cadherin, fibronectin, fibroblast specific protein-1 (FSP-1), $\alpha$-smooth muscle actin ( $\alpha$-SMA) (4-6).

The mechanisms of EMT has been studied for decades and it is now generally thought to be transcriptionally regulated $(4,5,14)$. These EMT-associated transcription factors, as referred to above, are regulated by various signaling pathways, including those activated by transforming growth factor- $\beta$ (TGF- $\beta$ ), Wnt, Notch, epidermal growth factor (EGF), fibroblast growth factor (FGF), hypoxia inducible factor (HIF), NF- $\mathrm{KB}$ and Sonic Hedgehog (Shh) signaling $(5,14,18)$. These pathways signal through triggering intracellular kinase cascades, which then operate in crosstalk to form a regulator network of EMT (5). In addition to the EMT-inducing transcription factors and their upstream signaling pathways, recent studies have further illustrated three additional regulatory mechanisms of EMT, including the expression of small noncoding RNAs (ncRNAs), alternative splicing and translational and post-translational modification $(14,18)$.

Intriguingly, a recent study by Rhim et al (19) has proposed that the EMT process seems to occur much earlier in tumor than expected. The lineage tracing system adopted by Rhim et al enables them to specifically label and track pancreatic epithelial cells in genetically engineered mouse model of pancreatic intraepithelial neoplasia (PanIN). To their surprise, the labeled pancreatic cells are detected in adjacent tissues and circulating system unexpectedly early, even before the formation of an identifiable primary tumor (19). The theory that EMT and the breach of basement membrane occurs prior to tumor formation probably shed some light on the aggressiveness of pancreatic cancer and other GI cancers, where many patients have already progressed to late stage upon presentation of the disease. This speculation underscores the urgency to better understand the mechanisms of EMT so as to manage the aggressiveness of GI cancer.

\section{Oncogenic role of STAT3 in GI cancer}

STAT3 was originally discovered as a latent cytoplasmic transcription factor that was activated by interleukin-6 (IL-6) 
Table I. Deregulated activation of STAT3 in GI cancer cell lines and tumor specimens.

\begin{tabular}{|c|c|c|c|c|}
\hline GI cancer & Cancer cell lines & Tumor specimens & Correlated genes & Refs. \\
\hline Pancreatic cancer & $\begin{array}{l}\text { SW1990, PANC-1, } \\
\text { BxPc-3, FG, Capan-1, } \\
\text { Capan-2, MiaPaCa }\end{array}$ & $\begin{array}{l}\text { Pancreatic ductal } \\
\text { adenocarcinoma }\end{array}$ & $\begin{array}{l}\text { Cyclin-D2, VEGF, } \\
\text { MMP-2, ZEB1, } \\
\text { E-cadherin }\end{array}$ & $(12,38,41,46,131)$ \\
\hline Gastric cancer & $\begin{array}{l}\text { AGS, MKN1, MKN7, } \\
\text { MKN28, HCG } 27\end{array}$ & Gastric adenocarcinoma & $\begin{array}{l}\text { Survivin, } \\
\text { VEGF, Bcl-2 }\end{array}$ & $(10,23)$ \\
\hline Colorectal cancer & $\begin{array}{l}\text { HT-29, CoGa-1, SW480, } \\
\text { SW1116, LoVo }\end{array}$ & Colorectal carcinoma & $\begin{array}{l}\text { MMP1, } \beta \text {-catenin, } \\
\text { ZEB1, E-cadherin, }\end{array}$ & $(11,49,121,159)$ \\
\hline Liver cancer & HCCLM3 & Hepatocellular carcinoma & $\begin{array}{l}\text { VEGF, survivin, } \\
\text { MMP-2, MMP-9 }\end{array}$ & $(13,39)$ \\
\hline Esophageal cancer & $\begin{array}{l}\text { EC9706, EC 109, } \\
\text { KYSE80, 150, 410, } 510\end{array}$ & $\begin{array}{l}\text { Esophageal squamous } \\
\text { cell carcinoma }\end{array}$ & $\beta$-catenin & $(161)$ \\
\hline
\end{tabular}

VEGF, vascular endothelial growth factor; MMPs, matrix metalloproteinases.

and EGF (20). Generally, activation of STAT3 relies on the phosphorylation of a conserved tyrosine residue (Y705) by upstream tyrosine kinases, including growth factor receptors, cytokine receptor-associated Janus kinase (JAK), as well as cytoplasmic tyrosine kinases, such as Src and Abelson kinase (ABL) $(9,21,22)$. Specifically, STAT3 can be activated by growth factor receptors that have intrinsic tyrosine kinase activity, such as epidermal growth factor receptor (EGFR) and platelet-derived growth factor receptor (PDGFR). Unlike receptor tyrosine kinases (RTKs), many cytokine receptors like IL-6 family cytokines, do not have intrinsic tyrosine kinase activity. In that case, the receptor-associated tyrosine kinases, typically JAK, are recruited upon ligand engagement and then activated to phosphorylate STAT3 $(9,21)$. In addition to IL-6 receptors, recent studies have identified Toll-like receptors (TLRs) and G-protein-coupled receptors (GPCRs) as novel activators of JAK-STAT3 pathway (22), which also exert tumor-promoting effects. Once phosphorylated, these STAT3 monomers form dimers through the reciprocal interactions of Src homology2 (SH2) domain and then translocate into the nucleus, where the dimer can directly regulate expression of the target genes by binding to specific DNA sequences (9).

Activation of STAT3 in normal cells is rapid and transient, mainly due to the negative regulation of STAT3 by suppressor of cytokine signaling (SOCS) and protein inhibitor of activated STAT (PIAS) (9). However, in contrast to that of normal cells, persistent activation of STAT3 has been frequently detected in a variety of human cancer cell lines and tissues, especially those of GI cancer (Table I), including gastric cancer $(10,23)$, colorectal cancer (11), pancreatic cancer (12) and hepatocellular carcinoma (HCC) (13). Despite the undefined mechanism of STAT3 constitutive activation in tumor, strong biological bases have supported this protein as an oncogenic driver, and consequently, have validated STAT3 as a promising target for cancer therapy $(21,24)$.

Constitutive activation of STAT3 is required for tumorigenesis of many GI cancers, including pancreatic cancer (25), HCC (26), gastric cancer and colon cancer (27). One of the earliest clues for the role of STAT3 in tumorigenesis was its association with malignant transformation. Compelling evidence was given when STAT3C, a constitutively activated mutant form of STAT3, transformed immortalized fibroblasts in vitro and caused tumor formation in mice (28). Other clues for its link with cancer came from the subsequent findings that STAT3 contributed to tumor growth and survival. As an oncoprotein, aberrant activation of STAT3 prevented apoptosis by upregulating the anti-apoptotic Bcl-2 family genes Bcl-xL and MCL1, as well as survivin, a member of the inhibitor of apoptosis (IAP) family (9). Also, STAT3 signaling has been implicated in the regulation of cellular proliferation, which is dependent on STAT3-induced expression of c-Myc and cyclin D1 (9). As a consequence, blocking STAT3 signaling was often sufficient to induce growth arrest and apoptosis in many different cancer types, in turn demonstrating the oncogenic properties of STAT3 $(21,24)$.

Notably, except for the classic oncogenic functions of STAT3 mentioned above, in recent years, the role of STAT3 in inflammatory-associated tumorigenesis, cancer metastasis and stemness have become topics of particular interest (Fig. 2). We then take closer look into these three parts.

Role of STAT3 in inflammatory-associated tumorigenesis of GI cancer. Inflammation virtually exists in every neoplastic lesion and contributes to tumorigenesis and progression by supplying immune factors that promote proliferation, survival, angiogenesis, invasion and metastasis. In particular, chronic inflammation is typically involved in tumorigenesis of gastrointestinal and hepatobiliary organs, including Helicobacter pylori (H.pylori) infection being a risk factor for gastric cancer and MALT lymphoma, inflammatory bowel diseases (IBD) for colorectal cancer, chronic virus hepatitis for HCC, Barrett's esophagus for esophageal cancer and chronic pancreatitis for pancreatic ductal adenocarcinoma (PDAC).

STAT3 is a transcription factor aberrantly activated in most GI cancers and has both potent pro-inflammation and oncogenic properties. It is therefore conceivable that STAT3 plays an important role in facilitating a tumor-promoting inflammatory microenvironment in GI cancer (29). For example, 


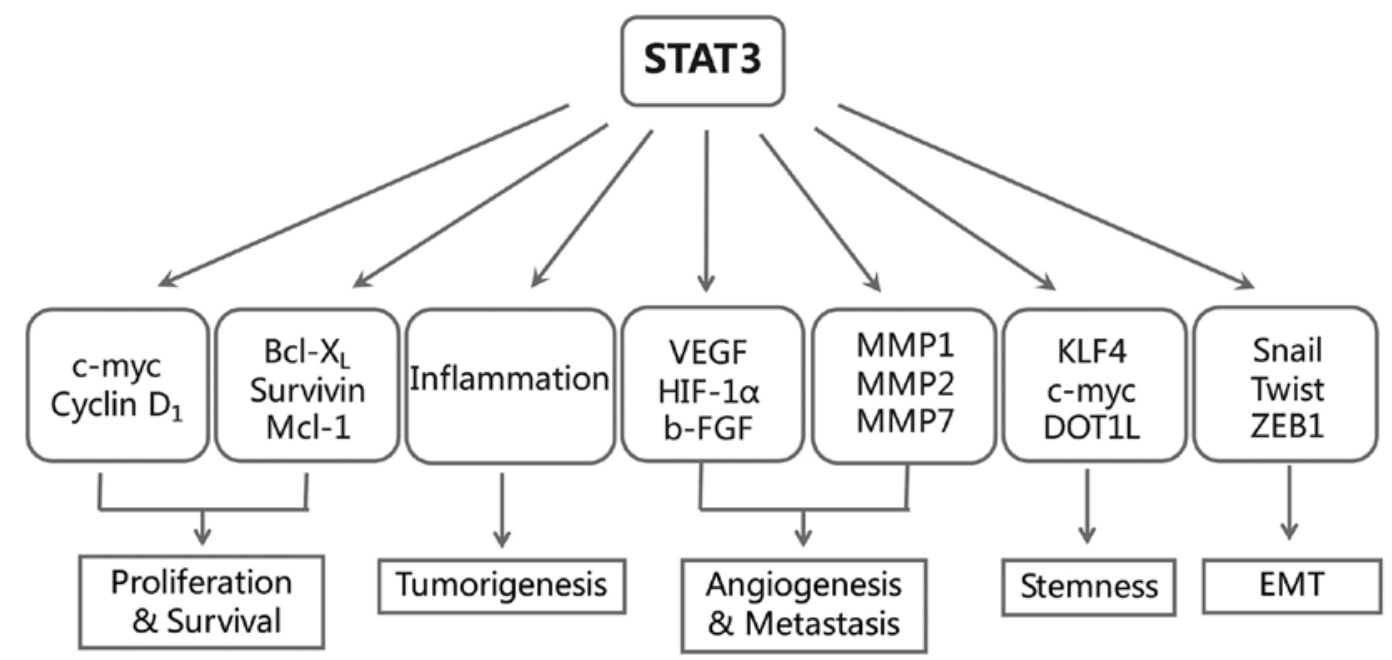

Figure 2. Oncogenic role of STAT3 in GI cancer. STAT3 acts as the critical 'switch' that controls the expression program of various tumor-associated genes, whereby it is involved in diverse biological processes of GI malignancies including proliferation, apoptosis, angiogenesis, invasion and metastasis. Notably, in recent years, STAT3 has been shown to possess great potential in inflammation-associated tumorigenesis, CSC generation and EMT induction.

chronic pancreatitis is a well-known risk factor for PDAC. The inflammatory mediator STAT3 has been demonstrated to be an essential component of the permissive environment provided by pancreatitis to drive the formation of KRAS-dependent PDAC precursor and its subsequent progression $(30,31)$. In the setting of both acute and chronic pancreatitis, deletion of STAT3 in transgenic mice expressing $\mathrm{KRAS}^{\mathrm{G} 12 \mathrm{D}}$ interferes with the acinar to ductal de-differentiation, resulting in fewer PanINs formation (30). Corresponding to the previous study that IL-17, mainly produced by Th17 and IL- $17^{+} / \gamma \delta \mathrm{T}$ cells recruited to the stroma of pancreatic cancer, can promote PanIN initiation and progression in cooperation with IL-6/STAT3 signaling (32), Loncle et al (33) have recently discovered that STAT3 is also involved in a novel REG3ß-JAK2-STAT3 inflammatory signaling triggered by IL-17 and propels transitional process from chronic pancreatitis to PDAC.

However, this linking role played by STAT3 appears to be ubiquitous in GI cancer, not restricted solely to pancreatic cancer. Sphingosine-1-phosphate receptor 1 (S1PR1), a GPCR that responds to the lipid metabolic signaling, is upregulated by STAT3 in tumors and reciprocally activates STAT3. Recently, Liang et al (34) elegantly demonstrated that sphingosine-1-phosphate (S1P) drives a malicious amplification loop involving SIPR1 and NF-кB/IL-6/STAT3, which links chronic intestinal inflammation to the occurring of colitis-associated cancer (CAC). A crucial role of STAT3 in the development of $\mathrm{CAC}$ is also supported by the finding that IL-6/STAT3 functions as a pro-tumorigenic signaling in the model of CAC (35). In the CAC model induced by dextran sulphate sodium (DSS), IL-6 activates STAT3 and promotes the survival of pre-malignant intestinal epithelial cells, which curbs their chance to further mutate or to subsequently form tumors (35). However, in gastric cancer, Ernst et al (36) demonstrated that it is IL-11, but not IL-6, that leads to abnormal activation of STAT3 and selectively triggers gastric adenoma formation in gp130 ${ }^{\mathrm{Y} 757 \mathrm{~F}}$ mice.

In conclusion, STAT3 may assume a central node and a checkpoint during inflammation-associated tumorigenesis, which has been demonstrated to be one of the most important pathogenic mechanisms of GI cancers.
Role of STAT3 in angiogenesis, invasion and metastasis of GI cancer. Tumors cannot sustain their growth or survive at a second site unless they are supplied with enough nutrients and oxygen from newly formed blood vessels. The role of STAT3 in tumor angiogenesis was first identified when vascular endothelial growth factor (VEGF), one of the most potent angiogenic factor, was demonstrated to be a target of STAT3 in various cancers including pancreatic cancer, gastric cancer and HCC (23,37-39). An activated STAT3 mutant (STAT3C) was found to upregulate VEGF expression and stimulate tumor angiogenesis in pancreatic cancer, while interrupting STAT3 signaling with dominant-negative Stat3 protein significantly abrogated this effect and suppressed tumor growth and metastasis in vivo (38). In support of this, we have shown that silencing STAT3 by RNAi led to decrease of VEGF and matrix metalloproteinase-2 (MMP-2) at both mRNA and protein levels in pancreatic cancer cells (40). Besides, by analyzing 71 pancreatic adenocarcinoma specimens, we found that the expression of p-STAT3 was clinically correlated with microvascular density (MVD), tumor size, TNM stage and lymphatic metastasis of pancreatic cancer, which may be partly attributed to its relationship with VEGF and VEGF-C (41). Here we propose that via upregulating VEGF-C, which acts on lymphatic endothelial cells to promote their proliferation and migration, STAT3 also contributes to the early lymphatic metastasis (41). In addition to directly binding to the VEGF promoter, STAT3 promotes tumor vascularization indirectly by controlling the expression of HIF-1 $\alpha$ (42), which acts as the final switch of VEGF expression. Furthermore, tumorassociated myeloid cells that display activated STAT3 also contribute to the production of VEGF and bFGF (43). By inducing these angiogenic factors, STAT3 activated in stroma cells functions to facilitate endothelium proliferation, migration and microtube formation (43).

Proteolytic enzymes such as MMPs are required for the degradation and remodeling of the extracellular matrix (ECM) and the basement membrane, which is a key step of tumor invasion and metastasis. It has been shown that STAT3 signaling enforces MMP-7 expression in pancreatic cancer 
cells and that MMP-7 deletion limits tumor size and metastasis in mice $(30,44)$. Except for MMP-7, MMP-2 has been identified as another target of STAT3 and also contributes to tumor invasion and metastasis (45). In line with this, we reported a reduced expression of MMP-2 in pancreatic cancer cells caused by STAT3 inhibition, which may account for the impaired invasion ability observed in vitro and in vivo (46-48). Similarly, p-STAT3 was also shown co-localized with MMP-1 in colorectal cancer and was later demonstrated to experimentally regulate the expression of MMP-1 (49). Therefore, by inducing diverse MMPs such as MMP-1, MMP-2 and MMP-7, STAT3 plays a major role during the invasion and infiltration of GI cancers.

As we discussed above, a crucial role of STAT3 in cancer cell proliferation, survival, angiogenesis and invasion has been well documented. It is reasonable to speculate that STAT3 also contributes to cancer metastasis since metastatic potential depends on multiple factors that determine the growth, apoptosis, angiogenesis, and invasion of cancer cells. For example, gain- and loss- of function model demonstrated that STAT3 promoted brain metastasis in melanoma via dysregulated expression of bFGF, VEGF and MMP-2 (50). A study using an orthotropic mouse model of pancreatic cancer showed that blockade of STAT3 via ectopic expression of dominantnegative STAT3 markedly reduced the incidence of liver metastasis as well as angiogenesis (38). Similarly, in mice bearing orthotopically implanted HCC cells, inhibition of STAT3 with anti-sense oligonucleotide resulted in decreased vascularization, local transmission and lung metastasis, along with an impaired expression of VEGF, bFGF, MMP-2 and MMP-9 (39).

Furthermore, STAT3 abnormally activated in cancer microenvironment also contributes to the metastasis cascade. For example, STAT3 activated in immune cells has been well illustrated to play an immunosuppressive role during cancer development, which facilitates the dissemination and colonization of cancer cells $(51,52)$. Additionally, a recent study by Deng et al (53) suggests an involvement of S1PR1JAK2-STAT3 signaling in establishing pre-metastatic niches in various cancers. These pre-metastatic niches, are mainly comprised of immune cells including myeloid cells, provide a sanctuary for disseminated cancer cells to colonize and form metastases at the hostile distant sites. Of note, both the migration and outgrowth of myeloid cells at distant organs require the signaling of S1PR1-STAT3. As expected, inhibiting STAT3 in myeloid compartment disrupts the existing premetastatic niches, as well as the subsequent metastasis (53). Taken together, constitutive activation of STAT3 in GI cancer functions to promote cancer progression by facilitating angiogenesis, invasion and metastasis.

Role of STAT3 in CSC generation of GI cancer. CSCs are defined as a subpopulation of tumor cells that sustain selfrenewal and are particularly resistant to conventional therapies. Several lines of evidence have demonstrated that STAT3 plays an essential role in promoting and maintaining the stemness of GI cancers (22).

STAT3 is constitutively activated in colon cancer-initiating cells marked with aldehyde dehydrogenase (ALDH) and CD133 positive (54). Except for these two molecular signatures, CD44 has also been recognized as a marker for CSC of colon cancer which potentially links with STAT3. A recent study (55) has found that CD44, when internalized and translocated to the nucleus, interacts with acetylated STAT3 and together binds to the promoters of target genes, such as c-myc and twist. This nuclear CD44/acetylated-STAT3 complex then functions to reprogram cancer cells to CSC-like cells (55). Similarly, in liver cancer, CD24 ${ }^{+} \mathrm{HCC}$ cells possess characteristics of stem cells and CD24 has been found to drive tumor initiation and self-renewal through STAT3-mediated upregulation of NANOG (56). In addition, it has also been shown that IL-6/STAT3 signaling upregulated expression of another CSC marker CD133 and promoted liver carcinogenesis (57).

Leukemia inhibitory factor (LIF)/STAT3 pathway has been extensively studied as a potent inducer of mouse embryonic stem cell self-renewal $(22,58)$. Efforts to delineate the downstream effector of LIF signaling has identified Krüppel-like factor 4 (KLF4) as a direct target of STAT3 (58), while KLF4 is known as a reprogramming factor important for stem cell maintenance and prevention of differentiation. Except for LIF, IL-6 is also involved in promoting STAT3-mediated CSC expansion in several types of malignancies $(59,60)$. Furthermore, immunosuppressive cells, including myeloid derived suppressor cells (MDSCs) and tumor-associated macrophages (TAMs), enhanced CSC subpopulation and promoted tumorigenesis in pancreatic cancer and $\mathrm{HCC}$ mainly through IL-6/STAT3 signaling $(61,62)$. More recently, Kryczek et al (63) have revealed a novel mechanism by which the IL-22/STAT3 signaling operates to increase cancer stemness as well as tumorigenic potential in colorectal cancer. DOT1L, histone 3 lysine 79 (H3K79) methyltransferase, was induced by STAT3 activation and then operative to upregulate the expression of three core stem cell genes, namely NANOG, Sox 2 and Oct4, through methylation of H3K79 (63). Thus, STAT3-mediated epigenetic regulation has also been implicated in STAT3 induced CSC generation.

Collectively, these findings confirm that STAT3 indeed plays a critical role in cancer stemness during GI cancer development, though many mechanisms are still undefined. In recent years, it has been proposed that cancer cells enforced to undergo EMT process can simultaneously acquire CSC-like properties (8). Under that circumstance, our team has been seeking to determine whether STAT3 may assume one of the potential links between EMT and stemness in GI cancer, based on our findings and those of others of the extensive involvement of STAT3 in GI cancer EMT.

\section{Role of STAT3 in regulating EMT of GI cancer}

While STAT3 plays a critical role in the initiation and progression of GI cancer, it remains elusive whether the aberrant signaling also contributes to EMT, the early step of tumor invasion and metastasis. Recent studies have shed some light on the puzzle, suggesting that STAT3 plays a role in stimulating and controlling the rapid transition of cells between epithelial and mesenchymal phenotype, both in physiological and pathological conditions. For example, during wound healing, keratinocytes at the border of the wound recapitulate part of the EMT process. Deficient in STAT3, cell migration of keratinocytes in response to injury is severely compromised (64). By upregulating zinc 


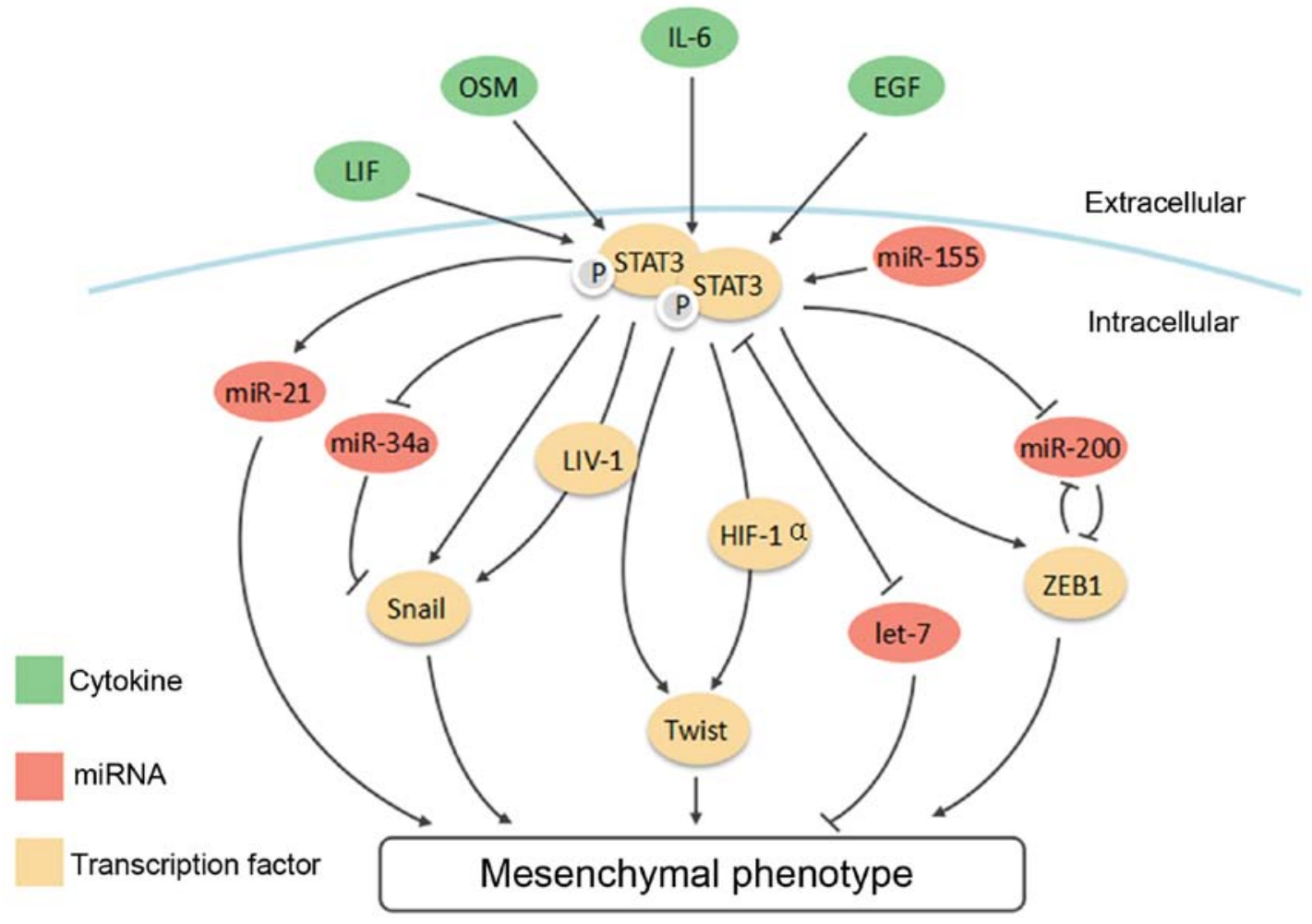

Figure 3. Possible mechanisms of STAT3-mediated EMT in GI cancer. STAT3 participates in multiple layers of EMT regulatory network. By upregulating EMT-transcription factors, including Snail, Twist and ZEB1, STAT3 integrates signals from various extracellular stimuli and is sufficient to induce a mesenchymal phenotype in GI cancers. Additionally, STAT3 interacts with the new EMT players non-coding RNAs, especially microRNAs, such as miR-34a, miR-21 and let-7, to further shift the epithelial and mesenchymal balance of cancer cells.

transporter LIV-1, STAT3 is essential for the migration of zebrafish gastrula organizer cells during its gastrulation (65).

Importantly, STAT3 has been cumulatively associated with the type 3 EMT, where it acts as a transcription activator of EMT-related genes in human cancers, especially in GI cancers (Table II). In this regard, we have recently uncovered the function of STAT3 in regulating EMT of pancreatic cancer (66). Treatment of IL-6 resulted in STAT3 abnormal activation and surprisingly, forced pancreatic cancer cells to experience typical EMT morphological changes, accompanied by an increased invasion ability and reduced E-cadherin expression $(66,67)$. Targeting STAT3 signaling either by siRNA or JAK inhibitor AG490 counteracted this effect $(46,66,67)$, indicating that activation of STAT3 is one of the prerequisites of IL-6-induced EMT in pancreatic cancer and it may comprise a target to combat EMT. Additionally, Liu et al (68) have recently demonstrated that aberrant activation of STAT3, but not the Akt or ERK, mediated Fos-related antigen-1 (Fra-1) upregulation in response to IL-6 in colon cancer cells. Fra-1 has been emerging as a central node of EMT and stemness in various cancer (69). By inducing Snail, Slug, ZEB1, as well as MMP-2 and MMP-9, the innovative IL-6/STAT3/Fra-1 signaling axis is responsible for EMT and metastasis of colorectal cancer (68).

Despite the above observations, the underlying mechanisms of STAT3-induced EMT are not fully understood as yet. To explore this, in the following sections, we will first discuss the ever-expanding connections between STAT3 and a list of 'master' EMT transcription factors, such as Snail, Twist1 and ZEB1, then unveil its interaction with the EMT new player, non-coding RNAs (Fig. 3). Since the regulatory network of EMT is rather complex and choreographed by multiple signaling pathways, we will finally look into crosstalk between STAT3 and other selected signaling pathways, including TGF- $\beta$, Notch and Wnt signaling.

\section{STAT3 and EMT-transcription factors}

STAT3 and Snail. Snail, a zinc finger protein encoded by SNAI1, is one of the master governors of EMT during embryogenesis, fibrosis as well as cancer progression (17). The role of Snail has been defined in tumor invasion, stemness, recurrence and immune suppression (70-72). Thus, overexpression of Snail is correlated with lymph node metastases and poor prognosis of patients with GI cancer, such as pancreatic cancer (73), gastric cancer (74), colorectal cancer (75) and liver cancer (76). Repression of epithelial genes by Snail requires its C-terminal directly binding to the 5'-CACCTG-3' elements present in the E-box of epithelial genes and its further recruitment and interactions with other co-repressors. Specifically, the SIN3A, histone deacetylase 1 (HDAC1), HDAC2 and polycomb repressive complex 2 (PRC2) are recruited by Snail upon its binding at E-cadherin promoter and then downregulate E-cadherin syngergistically through interacting with the SNAG sequence located at the N-terminal of Snail (77,78). Ubiquitin E3 ligase Ring1B and its paralog Ring1A also form repression complex with Snail, thereby promoting mesenchymal transformation of pancreatic cells through the C-terminal zinc finger domains of Snail (79).

As a master regulator of EMT, Snail is regulated by various signaling pathways, either at transcription or post-transcription 
Table II. Molecular changes associated with STAT3-mediated EMT in GI cancer.

\begin{tabular}{llllc}
\hline GI cancer & Epithelial markers $\uparrow$ & Mesenchymal markers $\downarrow$ & Downstream factors & Refs. \\
\hline Pancreatic cancer & E-cadherin & $\begin{array}{l}\text { N-cadherin, vimentin, } \\
\text { fibronectin }\end{array}$ & Snail & $(66,88,96)$ \\
Colorectal cancer & E-cadherin, ZO-1 & $\begin{array}{l}\text { N-cadherin, vimentin, } \\
\text { fibronectin }\end{array}$ & Fra-1, Slug, & ZEB1, Snail \\
Liver cancer & E-cadherin, $\beta$-catenin & N-cadherin, vimentin & Snail, Twist, LncTCF7 & $(67,93,121,129)$ \\
Gastric cancer & E-cadherin, ZO-1, & Vimentin & Twist, ZEB1, Slug & $(149,155)$ \\
& claudin-1 & & & \\
\hline
\end{tabular}

level. For example, SMAD3 and SMAD4 interact and form a complex with Snail to repress Occludin and E-cadherin during TGF- $\beta$-driven EMT (80). Notch signaling is required for hypoxia-induced tumor cells EMT and invasion by controlling the expression of Snail (81). An important modification mechanism of Snail is the phosphorylation by glycogen synthase kinase-3 $\beta$ (GSK-3 $\beta$ ), which leads to both nuclear export and ubiquitin-mediated degradation of Snail (82). Accordingly, several pathways, such as Wnt, PI3K/Akt and NF- $\kappa \mathrm{B}$, increase Snail activity by alleviating the phosphorylation by GSK-3 $\beta$ or disrupting the interaction between these two molecules $(82,83)$.

Apart from the classic signaling pathways mentioned above, STAT3 has been emerging as a novel regulator of Snail in GI cancer. As mentioned before, STAT3 transactivates LIV-1 during gastrulation in zebrafish, which then mediates the nuclear localization of Snail and the repression of E-cadherin (62). In addition to embryonic development, 76.4\% pancreatic cancer tissues (84) and 61\% liver cancer tissues (85) showed abnormal expression of LIV-1, which was clinically correlated with tumor size and lymphatic metastases. An investigation (86) into breast cancer cell lines has further confirmed the association between STAT3 and LIV-1. It proposed that the $\mathrm{Zn} 2^{+}$influx triggered by the zinc transporter LIV-1 and STAT3 functioned to inactivate GSK-3 $\beta$, rendering it unable to phosphorylate Snail, which in turn stabilizes the Snail protein (86). However, whether the same mechanism exists in GI cancer has not been reported yet. Therefore, our team has been working on it, hoping to further explain the mechanism by which STAT3 enhances the expression of Snail.

Additionally, Snail is also directly targeted by transcription factor STAT3 in diverse epithelial cancers $(66,87,88)$. IL-6 promotes head and neck tumor EMT via JAK/STAT3/Snail signaling (87). Consistently, we have previously shown that activation of STAT3 in response to IL-6 caused a series of EMT-related changes in pancreatic cancer, mainly by targeting Snail (66). STAT3 can also act as a mediator that converges the signals of TGF- $\beta$ and Ras and is thus indispensable for the induction of Snail during pancreatic cancer progression (88). NDRG2, a member of N-myc downstream regulated gene 2 (NDRG) family, has been reported as a tumor suppressor gene in various GI cancers including colon, liver and pancreatic cancer (89). It was shown that upregulation of NDRG2 inactivated STAT3-Snail signaling and thus impaired the EMT potential of cancer cells $(90,91)$, in turn demonstrating that STAT3/Snail signaling is critical for the invasion of cancer cells.
Furthermore, this malicious STAT3/Snail axis is also associated with CSC genes $(92,93)$. For example, STAT3/Snail signaling could be operative in HCC cells co-expressing Oct4 and NANOG, to empower HCC cells with mesenchymal phenotype as well as CSC properties (92). Yao et al (93) recently identified insulin-like growth factor (IGF) and its downstream STAT3 as signaling pathway controlling the expression of NANOG in colorectal cancer (CRC) cells, which then activate Slug to impinge upon the EMT program. Inhibition of STAT3 in CRC cells not only attenuated migration and invasion abilities, but also impaired the self-renewal of CRCs due to the reduced expression of NANOG (93). The potential link of the key stem cell genes and STAT3/Snail or STAT3/Slug established here may further confirm the obscure association between stemness and EMT in GI cancer.

Except for tumor cell itself, the surrounding stroma functions and constantly communicates with tumor cells to promote an invasive and drug-resistant phenotype. In particular, the release of interleukins by immune cells, endothelial cells and fibroblasts instruct tumor cells to undergo the EMT program (94). Recently, an attempt to characterize the role of immune-related cytokines in tumor microenvironment has identified IL-8 derived from macrophage as the chief one that dominates EMT process in HCC (95). The JAK2/STAT3 lies downstream of this IL-8 signaling, conveys the extracellular stimuli into the nuclear, and switches the epithelial phenotype of HCC cells into mesenchymal one via activating Snail (95). It has also been shown that pancreatic cancer cells treated with conditioned medium of pancreatic stellate cells (PSCs) exhibited enhanced migration ability and expression of mesenchymal markers $(96,97)$. This effect was attributed to the enriched IL- 6 secreted by PSCs and subsequent activation of STAT3 and Snail within cancer cells (96), whereas a possible role of TGF- $\beta$ in this process was excluded (97).

STAT3 and Twist. As a bHLH transcription factor, Twist forms homo- or hetero-dimers to repress epithelial genes and activate mesenchymal genes that define the EMT phenotype, leading to disassembly of epithelial junctions and disruption of cellular polarity (98). Overexpression of Twist is responsible for the poor prognosis of GI tumors, including hepatocellular carcinoma (76), esophageal squamous cell carcinoma (99), gastric cancer (100), colorectal cancer (75) and pancreatic cancer (101). Recently, EMT and its reverse process, mesenchymal-epithelial transition (MET) has received much attention. Interestingly, this reversible EMT pattern contributing 
to different stages of metastasis was implemented by dynamic expression of Twist (102). Turning on Twist conferred cancer cells with invasive properties, facilitating delamination and intravasation, while shutdown of Twist and the resultant initiation of MET program allowed the disseminated cells to restore an epithelial phenotype, acquiring capacities to proliferate and further form macrometastases in distant sites (102).

Among the multiple upstream signaling pathways, HIF-1 $\alpha$ is a critical one that binds to the hypoxia-response element in the Twist promoter and enhances its expression, thereby initiating the metastatic cascade in response to intratumoral hypoxia (103). Twist is also subject to posttranscriptional modification. Activation of MAPK, either by TGF- $\beta$ or Ras signaling, has been shown to phosphorylate Twist at Ser68, preventing it from ubiquitination and degradation (104). Moreover, phosphorylated Twist by Akt/protein kinase B (PKB) can target TGF- $\beta 2$ transcriptionally and further promotes metastasis by enhancing TGF- $\beta$ receptor signaling (105). As with Snail, Twist interacts with several components of the Mi2/nucleosome remodeling and deacetylase (Mi2/NuRD) complex to repress E-cadherin synergistically (106). Of note, the stemness factor Bmil has been identified as a transcriptional target of Twist (107). Once activated by Twist, Bmil acts in a concerted fashion with Twist to repress E-cadherin and the cell cycle inhibitor p16 (also known as INK4 $\alpha$ ) simultaneously, thus conferring tumor with migrating and self-renewing abilities (107).

Except for the signaling pathways mentioned above, the STAT3/Twist signaling has also been recognized to orchestrate EMT in diverse malignancies including GI cancer. The interaction was first discovered in breast cancer cells $(108,109)$. Activation of STAT3 induced Twist expression at mRNA and protein levels and promoted migration, invasion and colony formation of breast cancer cells. Mechanistically, activated STAT3 can directly bind to the second proximal STAT3-binding site on Twist promoter and transcriptionally upregulate its expression (108). IL-6 functions as an inducer of EMT phenotype in breast cancer through activating STAT3 and Twist (109). Furthermore, enforced expression of Twist augments the production of IL-6, giving rise to an autocrine activation of STAT3 and positive feedback of EMT (109). Conceivably, this cooperation between STAT3 and Twist also exists in GI cancer. For example, Twist has been found to be transcriptionally activated by STAT3 in HCC (110). Furthermore, STAT3-mediated Twist expression and EMT process can be triggered by EGF/EGFR signaling as well $(111,112)$. During this process, STAT3 induces Twist directly or indirectly via stabilizing HIF-1 $\alpha$ protein, which is another important stimulator of Twist expression (103). Clinical evidence has shown the level of Twist correlates strongly with that of p-STAT3 in late stage tumor tissues $(108,112)$, underscoring the significance of STAT3/ Twist signaling during tumor progression.

STAT3 and ZEB1. Abnormal expression of ZEB1 has been observed in many GI cancers, such as pancreatic cancer, gastric cancer, colon cancer, and liver cancer (113). The two zinc-finger clusters contained by ZEB1 are highly conserved and critical for its binding ability at the promoter of target genes, such as CDH1, the gene encoding E-cadherin (113). Like Snail and Twist, ZEB1-mediated transcription repression of epithelial genes also involves recruitment of co-repressors, such as C-terminal-binding protein (CtBP) (114) and SWI/SNF chromatin remodeling protein BRGI (115). Additionally, ZEB1 has been shown to recruit HDAC1 and HDAC2 specifically to the $\mathrm{CDH} 1$ promoter in pancreatic cancer, resulting in histone deacetylation and repression of the gene (116).

In the hierarchical structure of EMT-TFs, Snail controls ZEB1 expression at different levels and cooperates with Twist during the induction of ZEB1 (117). Additionally, diverse signaling pathways have already been shown to activate ZEB1 expression during embryonic development and tumorigenesis, such as TGF- $\beta$, Wnt, NF- $\kappa$ B, HIF signaling (113). Of note, the reciprocal regulation between ZEB proteins and miR-200 family has been well established in recent years $(118,119)$. miR-200 members were first found to maintain an epithelial phenotype of tumor cells by directly targeting ZEB1 and ZEB2 (118). Later study, however, identified miR-200 as targets of ZEB1 as well (119). Thus miR-200 and ZEB1 form a double-negative feedback loop that finely tunes the EMT process. Strikingly, via suppressing stemness-inhibiting miRNA such as miR-200c, miR-203 and miR-183, the EMT activator ZEB1 also contributes to the stem cell properties of tumor cells indirectly by rescuing the expression of stem cell factors, primarily Bmil, Sox 2 and KLF4, which are otherwise inhibited by these miRNAs (120).

Likewise, ZEB1 has also been shown to be transcriptionally regulated by STAT3. A STAT3/ZEB1/E-cadherin cascade is uncovered in several malignancies, particularly in colorectal cancer (CRC) (121-123). Xiong et al (121) found that activation of STAT3 dramatically increased CRC cell invasiveness and resistance to apoptosis. Mechanistically, STAT3 enhance the expression of ZEB1 and as a result, triggered the EMT program in CRC. In support of this, a recent study has confirmed the existence of STAT3/ZEB1 axis in colorectal cancer, proposing that blocking STAT3/ZEB1 signaling by IL-32 $\theta$ can inhibit EMT as well as stemness in tumor cells (123). Although IL-32 was previously shown to promote gastric cancer metastasis (124), IL-32 $\theta$, the newly discovered isoform of IL-32, was demonstrated to reduce the metastatic potential by directly binding to STAT3 and interfering with its nuclear translocation. An impaired self-renewal ability has also been observed in the IL-320-overexpressing cells, which was then attributed to the downregulation of ZEB1 and Bmil (123). The expression of p-STAT3 and ZEB1 are significantly correlated with tumor size and metastasis stages of CRC patients (121), further supporting the clinical association between STAT3 and ZEB1.

However, research in this field is relatively insufficient, and most efforts are restricted to colorectal cancer. Whether this collaboration between STAT3 and ZEB1 also exists in other GI cancers needs to be further explored.

Interactions between STAT3 and non-coding RNA. Non-coding RNAs (ncRNAs) refer to a group of RNAs that are not translated into proteins. ncRNAs are highly abundant and contain many functionally important RNAs. For example, transfer RNA (tRNA), ribosomal RNA (rRNA), small nuclear RNAs (snRNAs), and small nucleolar (snoRNAs) are required for critical biological processes, such as protein synthesis, RNA splicing and nuclear organization. Importantly, some other ncRNAs, specifically microRNAs (miRNAs), long 
non-coding RNAs (lncRNAs) and circular RNAs (circRNAs), have been reported to play regulatory roles in cancer pathogenesis, including cancer proliferation, apoptosis, angiogenesis and invasion.

Compelling evidence has shown the interactions between STAT3 and the regulatory ncRNAs during GI cancer initiation and progression (125). Herein we mainly focus on their contribution to EMT and metastasis, by summarizing which we further conclude to have the role of STAT3 in coordinating the regulatory circuit of EMT-related transcription factors and ncRNAs.

Interaction with microRNA. miRNAs are now commonly recognized as potent modifiers of gene expression profiles in many biological and pathological processes. These small non-coding RNA molecules, generally single strands of nucleotides $<22$, regulate genes expression by binding to the 3'-untranslated regions (3'-UTR) of their target mRNAs and then inducing translation repression and/or mRNAs degradation. In particular, emerging evidence has shown that some miRNAs are able to define the cellular phenotype through interactions with transcription regulators of EMT (18). Among these miRNAs, miR-200 family and miR-34 are undoubtedly the most characteristic ones. As mentioned above, miR-200 family members are described as gatekeepers of epithelial phenotype by reciprocally repressing ZEB family of transcription factors $(118,119)$. Similarly, miR-34 and Snail also form a double negative feedback loop to control cellular plasticity (126). Both miR-200s and miR-34 are positively modulated by p53 $(127,128)$. Therefore, loss of p53 function, which occurs frequently during cancer development, leads to repression of these miRNAs and further facilitates the transition of epithelial cells into mesenchymal, migratory ones (127).

Interaction with tumor suppressing microRNA $m i R-34$. Recently, Rokavec et al (129) proposed an IL-6/ STAT3/miR-34a feedback loop that drives mesenchymal phenotype in various carcinomas, including CRC. Upon exposure to IL-6, CRC cells underwent a typical EMT process, which was mechanistically attributed to the activation of STAT3 and its direct repression on miR-34a, one of the most characteristic miRNAs that impeded the EMT process. It was then found that miR-34a also targeted the IL-6 receptor and thus interrupted the IL-6/STAT3/miR34a signaling. Therefore, the repression of miR-34 by STAT3 activation in turn reinforced the feedback loop (129). Rokavec et al then provided in vivo evidence by knocking down miR-34a in a mouse model of colitis-associated cancer. Deficiency in miR-34a further facilitated the IL-6-STAT3-mediating tumorigenesis and strikingly, enabled the tumor progress to an invasive one, which has not been observed in the same CAC model with intact expression of miR-34a (35).

Let-7. In addition to miR-34, STAT3 has also been shown to downregulate miR-200 and let-7 (130). STAT3 was activated upon oncostatin M (OSM) treatment and mediated the phenotypic transition by driving two circuits, namely STAT3/ lin-28/let-7/HMGA2 and STAT3/miR-200/ZEB1 (130). While the relationship between miR-200 and ZEB1 has been well interpreted above, let-7 is another tumor suppressor shown to interact with STAT3 extensively. STAT3 inhibited let-7 by transactivating lin-28 $(125,130)$, whereas let-7 downregulated
STAT3 by increasing SOCS3 expression (131), one of the negative regulators of STAT3. Studies showed that upregulation of let-7 restored the sensitivity to cisplatin in esophageal squamous cell carcinoma (132) and impaired migration of pancreatic cancer cells (131), both due to the interrupted activation of STAT3. Notably, re-expressing let-7 and miR-200 reversed the EMT phenotype of gemcitabine-resistant pancreatic cancer cells (133). Since STAT3 has been shown to induce EMT via repressing let-7 and miR-200 (130), it is tempting to posit that targeting STAT3 in GI cancer may restore the expression of these two miRNAs and achieve the same favorable effect.

Interaction with oncogenic microRNA miR-21. miR-21 is overexpressed in a variety of GI tumors, including pancreatic cancer, esophageal cancer, colon cancer and cholangiocarcinoma $(134,135)$. It is generally considered to be oncogenic miRNA that targets tumor suppressor genes, such as programmed cell death 4 (PDCD4) and tissue inhibitor of metalloproteinase 3 (TIMP3) (135). Importantly, miR-21, containing 2 conserved STAT3 binding sites in its enhancer, is a typical miRNA lying downstream of STAT3 signaling (136). It is recently reported that miR-21 mediates the promoting effect of LIF/STAT3 on EMT and metastasis (137). LIF, via binding to its receptor complex LIF-R/gp130, can trigger distinct signaling pathways including JAK/STAT3, MAPK, ERK and AKT. Herein, LIF was shown to promote tumor cell acquisition of mesenchymal features depending on the induction of miR-21 by STAT3 (137). In line with this, STAT3/ miR-21 activation by IL- 6 was also shown to be required for arsenite-induced EMT of human bronchial epithelial cells (138), highlighting the association between STAT3 and its oncogenic partner miR-21 during EMT process.

$m i R-155$. Previous study has indicated that miR-155 is overexpressed in PDAC cell lines and acts as an oncogenic miRNA by repressing tumor protein 53 -induced nuclear protein 1 (TP53INP1) (139). We have recently found that the expression of miR-155 was correlated with lymph node metastases and clinical stages of pancreatic cancer (140). Furthermore, overexpression of miR-155 in pancreatic cancer cells played a causable role in the downregulation of SOCS1 and subsequent upregulation of STAT3, which then promoted emergence of EMT-related features, as enhanced invasion and migration. This is in tandem with another study showing that miR-155 can promote STAT3-mediated tumorigenesis in breast cancer by targeting SOCS1, one of the major suppressing factors of STAT3 activation (141).

Interaction with long non-coding RNA. IncRNAs are defined as non-protein coding transcripts longer than 200 nucleotides. Recently, an lncRNA activated by TGF- $\beta$ (IncRNA-ATB) was demonstrated to promote invasion and metastasis in HCC. By competitively binding miR-200 family, lncRNA-ATB upregulated ZEB1 and ZEB2, and thus induced the EMT process (142). Subsequently, an aberrant IL-6/STAT3/IncTCF7 signaling was observed in $\mathrm{HCC}$, which also contributes to the aggressiveness of the HCC via triggering EMT (143). These studies well present a new direction for future study by illustrating the novel involvement of lncRNA in EMT process and their possible association with EMT key regulators such as TGF- $\beta$ and STAT3. 
Interaction with circular RNA. circRNAs are a novel class of endogenous non-coding RNAs that also participates in the gene expression regulation. Unlike miRNAs and lncRNAs that are terminated with $5^{\prime}$ caps and $3^{\prime}$ tails, circRNAs form a covalently closed loop without accessible termini, rendering it stable and resistant to exonuclease-mediated degradation (144). Despite circRNAs being abundant in eukaryocytes, it was not noted until recent reports revealed that circRNAs could act as a miRNA sponge to inhibit its activity and thus regulate gene expression (145).

ciRS-7, presented with $>70$ conserved miR-7 binding sites, was able to bind to miR-7 efficiently and suppress its activity, which in turn increased levels of miR-7 targets (145). As a tumor-suppressing miRNA, miR-7 has been shown to reverse EMT and impair metastasis in gastric cancer by targeting insulin-like growth factor receptor 1 (IGFR1) and indirectly downregulating Snail (146). In addition, miR-7 is severely depressed in colorectal cancer and serves as a tumor suppressor by targeting the oncogenic transcription factor Yin Yang 1 (YY1) (147). Therefore, it is tempting to speculate that ciRS-7 or some unknown circRNAs contribute to the silencing of tumor-suppressing miRNAs like miR-7 in GI cancer, thus giving rise to the expression of oncogenic transcription factors. For example, circRNA_001569 was recently identified as a sponge of miR-145 and functioned to upregulate miR-145 targets E2F5, BAG4 and FMNL2, resulting in enhanced proliferation and invasion of colorectal cancer cells (148).

From this perspective, we have recently noted a correlative expression of STAT3 and one of the circRNAs in diverse pancreatic cancer cell lines and tissues (data not shown). Our following experiments are aimed to find the possible link miRNAs between these two factors and to further define their exact function in EMT process of pancreatic cancer. Obviously, the emerging circRNAs and their mysterious interactions with miRNAs and transcription factors have prompted new and promising avenues to uncover the highly complex network of EMT regulation.

\section{Crosstalk with other signaling pathways}

Crosstalk between STAT3 and TGF- $\beta$ signaling pathways. TGF- $\beta$ is a poten inducer of EMT through both Smaddependent transcriptional events and Smad-independent signaling (149). Given the bi-directional role of TGF- $\beta$ in carcinogenesis, alterations in TGF- $\beta$ signaling that shift the tumor-promoting and tumor-suppressing balance is rather critical. Deletion of Smad4, one of the Smad family of signal transducers from TGF- $\beta$, occurs in up to $50 \%$ advanced pancreatic cancer, making it candidate for further investigation. Zhao et al (150) restored Smad4 expression in pancreatic cancer cells and observed an impaired ability in invasion and metastasis, which was later attributed to a Smad4-dependent suppression of STAT3Tyr705 phosphorylation. The researchers first established cross-talk between Smad4-independent TGF- $\beta$ signaling and STAT3 in pancreatic cancer where the persistent activation of STAT3 due to the loss of Smad4 cooperated with TGF- $\beta$ to promote an invasive lineage (150). The same synergistic effect of IL-6/ STAT3 and TGF- $\beta$ in inducing EMT was also observed in lung carcinomas in vitro, albeit here STAT3 was shown necessary for the canonical TGF- $\beta /$ Smad signaling (151).
Another study has shown that Snail expression was selectively induced by TGF- $\beta$ in pancreatic cells harboring mutated KRAS (88). Through this process, STAT3 acted as a crucial node that TGF- $\beta$ and Ras signals converged on. Treatment of TGF- $\beta$ relieved the interaction between STAT3 and its antagonist PIAS3, which instead bound to Smad3 and consequently, intensified the TGF- $\beta$ signaling. Interestingly, the dissociated STAT3 enhanced Snail expression and triggered EMT in some manner without binding to its canonical DNA-binding sites at Snail promoter (88). Taken together, there is tight crosstalk between STAT3 and the classic EMT-inducing signaling TGF- $\beta$, which may contribute to the EMT and invasion of GI cancers.

Crosstalk between STAT3 and Notch signaling pathways. Notch, one of the embryonic pathways of epithelial plasticity, has been associated with tumor recurrence and stemness partially by inducing EMT (152). Similar to TGF- $\beta$, Notch signaling is tightly involved in initiation and progression of GI cancer. Investigation on elevated Notch-2 and its ligand Jagged-1 in gemcitabine-resistant cancer cells uncovered that Notch signaling was mechanistically linked with acquisition of a mesenchymal phenotype in pancreatic cancer (153). Targeting both Notch and JAK2/STAT3 pharmacologically showed efficacy on cell growth and epithelial plasticity in pancreatic cancer, suggesting a favorable interplay between these two oncogenic pathways during cancer progression (154). Of note, in vitro and in vivo studies demonstrated the involvement of a novel Notch/STAT3/Twist cascade in gastric cancer cell growth and metastasis, where the interaction between p-STAT3 and the promoter of Twist was enforced by Notch1 receptor intracellular domain (N1IC) (155). Therefore, the Notch/STAT3/Twist cascade has been demonstrated to promote colony formation, migration and invasion in gastric cancer (155).

How does the activated Notch1 receptor promote STAT3 phosphorylation? One mechanism may be explained by the direct phosphorylation of STAT3 in the presence of Hes1 $(155,156)$, the most characteristic target of Notch signaling. Alternatively, Notch1 signaling may promote expression of cytokines that can subsequently activate STAT3. For example, Notch was reported to stimulate IL-6 expression in breast cancer cells and then drive both autocrine and paracrine JAK/ STAT3 signaling via a non-canonical mode, independent of Hes1 (157). Notably, the activation of jagged1/Notch by IL-6/ STAT3 was also identified in the development of trastuzumab resistance in gastric cancer cells (158). Prolonged treatment by trastuzumab induced EMT-like and drug-resistant phenotype in gastric cancer, which was attributed to the compensatory activation of STAT3 and its reciprocal activation of Notch signaling (158). Collectively, this reciprocal interaction between STAT3 and Notch signaling may be responsible for the invasion, stemness as well as drug resistance of GI cancers.

Crosstalk between STAT3 and Wnt signaling pathways. Wnt signaling is another signaling that potentially interacts with STAT3 to elicit the EMT process in GI cancer. In the absence of Wnt signals, $\beta$-catenin is phosphorylated by a complex of GSK-3 $\beta$, Axin and adenomatous polyposis coli (APC), which renders $\beta$-catenin sequestered in the cytoplasm. However, in canonical Wnt signaling, activation of the receptor Frizzled by Wnt ligands disrupts the formation of the complex and 
thus enables $\beta$-catenin to translocate into the nucleus, where $\beta$-catenin forms complex with $\mathrm{T}$ cell factor/lymphoid enhancing factor $(\mathrm{TCF} / \mathrm{LEF})$ family transcription factors and jointly binds to the promoter of their target genes, such as Snail, Slug and Twist (5).

Intriguingly, it has been suggested that activation of STAT3 may participate in the canonical Wnt signaling in GI cancer. For example, co-expression of p-STAT3 and $\beta$-catenin was observed in colorectal cancer tissues and was associated with worse prognosis (159). Subsequent in vitro experiment demonstrated that STAT3 activation is required for the nuclear accumulation of $\beta$-catenin, which is the commonly recognized key event for the development of colorectal cancer (159). Furthermore, a recent study has shown that STAT3 overexpression significantly increased the levels of $\beta$-catenin and $\mathrm{TCF} 1$, and further promoted the proliferation and survival of pancreatic cancer cells (160). Additionally, STAT3 was also regulated by $\beta$-catenin/TCF signaling (161). A functional TCF binding element was detected in the promoter of STAT3, and transfected $\beta$-catenin in esophageal cancer cells enhanced the expression of STAT3. It was then proposed that STAT3 is a target of $\beta$-catenin/TCF signaling and by upregulating STAT3, $\beta$-catenin/TCF promoted the esophageal tumorigenesis (161).

Apart from the mechanisms mentioned above, STAT3 has been recently implicated in a noncanonical Wnt signaling that regulates EMT in a wide range of solid tumors (162). Wnt 5a/b and their cognate receptor Fzd2 were found to be generally elevated in late-stage mesenchymal type malignancies including HCC and colon cancer. Following study revealed an unconventional mechanism of STAT3 activation process in these Wnt5-Fzd2-expressing tumor cells. Wnt receptor Frizzled2, when activated by its ligands, recruited tyrosine kinase Fyn, a Src family kinase, to phosphorylate STAT3 on Tyr705, and thus initiated the transcriptional program that ultimately drove the process of EMT, cellular migration and invasion (162). In brief, despite it is evident that STAT3 interacts with Wnt signaling in various GI cancers, it remains largely unknown how this crosstalk contributes to the cancer invasion and metastasis. Apparently, this needs to be further investigated.

\section{Conclusion and outlook}

Aberrant activation of STAT3 has been detected at high frequency in a majority of epithelial malignancies, including those of GI cancer. However, excessive STAT3 activation usually occurs in the absence of genetic mutation. Instead it often results from the autocrine and paracrine production of IL-6 family cytokines derived from tumor cells and stroma cells. These multiple oncogenic signaling pathways are responsible for the abnormal activation of STAT3 and are targets for further investigation. However, regardless of the undefined mechanisms of STAT3 activation in tumor cells, strong biological bases have supported it as an oncogenic driver involved in the initiation and progression of GI cancer.

In this review, we first summarized the role of STAT3 in GI cancer pathogenesis, particularly focusing on the processes of inflammatory-associated tumorigenesis, angiogenesis, invasion and metastasis, and CSCs generation. After that, we looked into the possible mechanisms of STAT3-mediated
EMT in GI cancer. On the basis of its extensive interaction with EMT-inducing transcription factors, miRNAs and other signaling pathways, a critical role of STAT3 in GI cancer EMT has been fundamentally established. However, studies of this part are not abundant. New players in EMT regulatory network such as miRNAs, lncRNAs and circRNAs are emerging quickly and more importantly, some of them can be therapeutically manipulated. Therefore, a comprehensive understanding of the aberrant STAT3 signaling cascade in GI malignancies and its association with these classic and novel regulators of EMT may hold great promise for the identification and validation of therapeutic targets that can effectively repress and control the aggressiveness of GI cancer.

\section{Acknowledgements}

This study was supported by grants from the Shanghai Health and Family Planning Commission (no. XYQ2013092), the Shanghai Municipal Human Resources and Social Security Bureau (nos. 2012040 and 13PJD024), the Shanghai Municipal Science and Technology Commission (no. 144119668) and the Shanghai Municipal Education Commission-Gaofeng Clinical Medicine Grant Support (no. 20161425).

\section{References}

1. Bjelakovic G, Nikolova D, Simonetti RG and Gluud C: Antioxidant supplements for preventing gastrointestinal cancers. Cochrane Database Syst Rev 3: CD004183, 2008.

2. Siegel RL, Miller KD and Jemal A: Cancer statistics, 2016. CA Cancer J Clin 66: 7-30, 2016.

3. Chen W, Zheng R, Baade PD, Zhang S, Zeng H, Bray F, Jemal A Yu XQ and He J: Cancer statistics in China, 2015. CA Cancer J Clin 66: 115-132, 2016.

4. Thiery JP, Acloque H, Huang RY and Nieto MA: Epithelialmesenchymal transitions in development and disease. Cell 139: 871-890, 2009.

5. Gonzalez DM and Medici D: Signaling mechanisms of the epithelial-mesenchymal transition. Sci Signal 7: re8, 2014.

6. Kalluri R and Weinberg RA: The basics of epithelial-mesenchymal transition. J Clin Invest 119: 1420-1428, 2009.

7. Zheng X, Carstens JL, Kim J, Scheible M, Kaye J, Sugimoto H, Wu CC, LeBleu VS and Kalluri R: Epithelial-to-mesenchymal transition is dispensable for metastasis but induces chemoresistance in pancreatic cancer. Nature 527: 525-530, 2015.

8. Mani SA, Guo W, Liao MJ, Eaton EN, Ayyanan A, Zhou AY, Brooks M, Reinhard F, Zhang CC, Shipitsin M, et al: The epithelial-mesenchymal transition generates cells with properties of stem cells. Cell 133: 704-715, 2008.

9. Yu H and Jove R: The STATs of cancer--new molecular targets come of age. Nat Rev Cancer 4: 97-105, 2004.

10. Kanda N, Seno H, Konda Y, Marusawa H, Kanai M, Nakajima T, Kawashima T, Nanakin A, Sawabu T, Uenoyama Y, et al: STAT3 is constitutively activated and supports cell survival in association with survivin expression in gastric cancer cells. Oncogene 23: 4921-4929, 2004.

11. Corvinus FM, Orth C, Moriggl R, Tsareva SA, Wagner S, Pfitzner EB, Baus D, Kaufmann R, Huber LA, Zatloukal K, et al: Persistent STAT3 activation in colon cancer is associated with enhanced cell proliferation and tumor growth. Neoplasia 7: 545-555, 2005.

12. Scholz A, Heinze S, Detjen KM, Peters M, Welzel M, Hauff P, Schirner M, Wiedenmann B and Rosewicz S: Activated signal transducer and activator of transcription 3 (STAT3) supports the malignant phenotype of human pancreatic cancer. Gastroenterology 125: 891-905, 2003.

13. Yang SF, Wang SN, Wu CF, Yeh YT, Chai CY, Chunag SC, Sheen MC and Lee KT: Altered p-STAT3 (tyr705) expression is associated with histological grading and intratumour microvessel density in hepatocellular carcinoma. J Clin Pathol 60: 642-648, 2007. 
14. De Craene B and Berx G: Regulatory networks defining EMT during cancer initiation and progression. Nat Rev Cancer 13: 97-110, 2013.

15. Pignatelli M, Ansari TW, Gunter P, Liu D, Hirano S, Takeichi M, Klöppel G and Lemoine NR: Loss of membranous E-cadherin expression in pancreatic cancer: Correlation with lymph node metastasis, high grade, and advanced stage. J Pathol 174: 243-248, 1994.

16. Lee SJ, Choi SY, Kim WJ, Ji M, Lee TG, Son BR, Yoon SM, Sung R, Lee EJ, Youn SJ, et al: Combined aberrant expression of E-cadherin and S100A4, but not $\beta$-catenin is associated with disease-free survival and overall survival in colorectal cancer patients. Diagn Pathol 8: 99, 2013.

17. Cano A, Pérez-Moreno MA, Rodrigo I, Locascio A, Blanco MJ, del Barrio MG, Portillo F and Nieto MA: The transcription factor snail controls epithelial-mesenchymal transitions by repressing E-cadherin expression. Nat Cell Biol 2: 76-83, 2000.

18. Lamouille S, Xu J and Derynck R: Molecular mechanisms of epithelial-mesenchymal transition. Nat Rev Mol Cell Biol 15: 178-196, 2014.

19. Rhim AD, Mirek ET, Aiello NM, Maitra A, Bailey JM, McAllister F, Reichert M, Beatty GL, Rustgi AK, Vonderheide RH, et al: EMT and dissemination precede pancreatic tumor formation. Cell 148: 349-361, 2012.

20. Zhong Z, Wen Z and Darnell JE Jr: Stat3: A STAT family member activated by tyrosine phosphorylation in response to epidermal growth factor and interleukin-6. Science 264: 95-98, 1994.

21. Turkson J: STAT proteins as novel targets for cancer drug discovery. Expert Opin Ther Targets 8: 409-422, 2004.

22. Yu H, Lee H, Herrmann A, Buettner R and Jove R: Revisiting STAT3 signalling in cancer: New and unexpected biological functions. Nat Rev Cancer 14: 736-746, 2014.

23. Choi JH, Ahn MJ, Park CK, Han HX, Kwon SJ, Lee YY and Kim IS: Phospho-Stat3 expression and correlation with VEGF, p53, and Bcl-2 in gastric carcinoma using tissue microarray. APMIS 114: 619-625, 2006.

24. Wake MS and Watson CJ: STAT3 the oncogene - still eluding therapy? FEBS J 282: 2600-2611, 2015.

25. Corcoran RB, Contino G, Deshpande V, Tzatsos A, Conrad C, Benes CH, Levy DE, Settleman J, Engelman JA and Bardeesy N: STAT3 plays a critical role in KRAS-induced pancreatic tumorigenesis. Cancer Res 71: 5020-5029, 2011.

26. Rebouissou S, Amessou M, Couchy G, Poussin K, Imbeaud S, Pilati C, Izard T, Balabaud C, Bioulac-Sage P and Zucman-Rossi J: Frequent in-frame somatic deletions activate gp130 in inflammatory hepatocellular tumours. Nature 457: 200-204, 2009.

27. Putoczki TL, Thiem S, Loving A, Busuttil RA, Wilson NJ Ziegler PK, Nguyen PM, Preaudet A, Farid R, Edwards KM, et al: Interleukin-11 is the dominant IL-6 family cytokine during gastrointestinal tumorigenesis and can be targeted therapeutically. Cancer Cell 24: 257-271, 2013.

28. Bromberg JF, Wrzeszczynska MH, Devgan G, Zhao Y, Pestell RG Albanese C and Darnell JE Jr: Stat3 as an oncogene. Cell 98 295-303, 1999.

29. Yu H, Pardoll D and Jove R: STATs in cancer inflammation and immunity: A leading role for STAT3. Nat Rev Cancer 9: 798-809, 2009.

30. Fukuda A, Wang SC, Morris JP IV, Folias AE, Liou A, Kim GE Akira S, Boucher KM, Firpo MA, Mulvihill SJ, et al: Stat3 and MMP7 contribute to pancreatic ductal adenocarcinoma initiation and progression. Cancer Cell 19: 441-455, 2011.

31. Lesina M, Kurkowski MU, Ludes K, Rose-John S, Treiber M, Klöppel G, Yoshimura A, Reindl W, Sipos B, Akira S, et al: Stat $3 /$ Socs 3 activation by IL- 6 transsignaling promotes progression of pancreatic intraepithelial neoplasia and development of pancreatic cancer. Cancer Cell 19: 456-469, 2011.

32. McAllister F, Bailey JM, Alsina J, Nirschl CJ, Sharma R, Fan H, Rattigan Y, Roeser JC, Lankapalli RH, Zhang H, et al: Oncogenic Kras activates a hematopoietic-to-epithelial IL-17 signaling axis in preinvasive pancreatic neoplasia. Cancer Cell 25: 621-637,2014

33. Loncle C, Bonjoch L, Folch-Puy E, Lopez-Millan MB, Lac S, Molejon MI, Chuluyan E, Cordelier P, Dubus P, Lomberk G, et al: IL17 functions through the novel REG3b-JAK2-STAT3 inflammatory pathway to promote the transition from chronic pancreatitis to pancreatic Cancer. Cancer Res 75: 4852-4862, 2015.

34. Liang J, Nagahashi M, Kim EY, Harikumar KB, Yamada A, Huang WC, Hait NC, Allegood JC, Price MM, Avni D, et al: Sphingosine-1-phosphate links persistent STAT3 activation, chronic intestinal inflammation, and development of colitisassociated cancer. Cancer Cell 23: 107-120, 2013.
35. Grivennikov S, Karin E, Terzic J, Mucida D, Yu GY, Vallabhapurapu S, Scheller J, Rose-John S, Cheroutre H, Eckmann L, et al: IL-6 and Stat3 are required for survival of intestinal epithelial cells and development of colitis-associated cancer. Cancer Cell 15: 103-113, 2009.

36. Ernst M, Najdovska M, Grail D, Lundgren-May T, Buchert M, Tye H, Matthews VB, Armes J, Bhathal PS, Hughes NR, et al: STAT3 and STAT1 mediate IL-11-dependent and inflammationassociated gastric tumorigenesis in gp130 receptor mutant mice. J Clin Invest 118: 1727-1738, 2008

37. Niu G, Wright KL, Huang M, Song L, Haura E, Turkson J, Zhang S, Wang T, Sinibaldi D, Coppola D, et al: Constitutive Stat3 activity upregulates VEGF expression and tumor angiogenesis. Oncogene 21: 2000-2008, 2002.

38. Wei D, Le X, Zheng L, Wang L, Frey JA, Gao AC, Peng Z, Huang S, Xiong HQ, Abbruzzese JL, et al: Stat 3 activation regulates the expression of vascular endothelial growth factor and human pancreatic cancer angiogenesis and metastasis. Oncogene 22: 319-329, 2003

39. Li WC, Ye SL, Sun RX, Liu YK, Tang ZY, Kim Y, Karras JG and Zhang $\mathrm{H}$ : Inhibition of growth and metastasis of human hepatocellular carcinoma by antisense oligonucleotide targeting signal transducer and activator of transcription 3. Clin Cancer Res 12: 7140-7148, 2006.

40. Huang C, Jiang T, Zhu L, Liu J, Cao J, Huang KJ and Qiu ZJ: STAT3-targeting RNA interference inhibits pancreatic cancer angiogenesis in vitro and in vivo. Int J Oncol 38: 1637-1644, 2011.

41. Huang C, Huang R, Chang W, Jiang T, Huang K, Cao J, Sun X and Qiu Z: The expression and clinical significance of pSTAT3, VEGF and VEGF-C in pancreatic adenocarcinoma. Neoplasma 59: 52-61, 2012

42. Xu Q, Briggs J, Park S, Niu G, Kortylewski M,Zhang S, Gritsko T, Turkson J, Kay H, Semenza GL, et al: Targeting Stat3 blocks both HIF-1 and VEGF expression induced by multiple oncogenic growth signaling pathways. Oncogene 24: 5552-5560, 2005.

43. Kujawski M, Kortylewski M, Lee H, Herrmann A, Kay H and Yu H: Stat 3 mediates myeloid cell-dependent tumor angiogenesis in mice. J Clin Invest 118: 3367-3377, 2008.

44. Li HD and Huang C, Huang KJ, Wu WD, Jiang T, Cao J, Feng ZZ and Qiu ZJ: STAT3 knockdown reduces pancreatic cancer invasiveness and matrix metalloproteinase-7 expression in nude mice. PLoS One 6: e25941, 2011.

45. Xie TX, Wei D, Liu M, Gao AC, Ali-Osman F, Sawaya R and Huang S: Stat 3 activation regulates the expression of matrix metalloproteinase-2 and tumor invasion and metastasis. Oncogene 23: 3550-3560, 2004.

46. Huang C, Cao J, Huang KJ, Zhang F, Jiang T, Zhu L and Qiu ZJ: Inhibition of STAT3 activity with AG490 decreases the invasion of human pancreatic cancer cells in vitro. Cancer Sci 97: $1417-1423,2006$

47. Qiu Z, Huang C, Sun J, Qiu W, Zhang J, Li H, Jiang T, Huang K and Cao J: RNA interference-mediated signal transducers and activators of transcription 3 gene silencing inhibits invasion and metastasis of human pancreatic cancer cells. Cancer Sci 98: 1099-1106, 2007

48. Yang G, Huang C, Cao J, Huang KJ, Jiang T and Qiu ZJ: Lentivirus-mediated shRNA interference targeting STAT3 inhibits human pancreatic cancer cell invasion. World J Gastroenterol 15: 3757-3766, 2009.

49. Tsareva SA, Moriggl R, Corvinus FM, Wiederanders B Schütz A, Kovacic B and Friedrich K: Signal transducer and activator of transcription 3 activation promotes invasive growth of colon carcinomas through matrix metalloproteinase induction. Neoplasia 9: 279-291, 2007.

50. Xie TX, Huang FJ, Aldape KD, Kang SH, Liu M, Gershenwald JE, Xie K, Sawaya R and Huang S: Activation of stat3 in human melanoma promotes brain metastasis. Cancer Res 66: 3188-3196, 2006.

51. Jones LM, Broz ML, Ranger JJ, Ozcelik J, Ahn R, Zuo D, Ursini-Siegel J, Hallett MT, Krummel M and Muller WJ: Stat3 establishes an immunosuppressive microenvironment during the early stages of breast carcinogenesis to promote tumor growth and metastasis. Cancer Res 76: 1416-1428, 2016.

52. Yu H, Kortylewski M and Pardoll D: Crosstalk between cancer and immune cells: Role of STAT3 in the tumour microenvironment. Nat Rev Immunol 7: 41-51, 2007.

53. Deng J, Liu Y, Lee H, Herrmann A, Zhang W, Zhang C, Shen S, Priceman SJ, Kujawski M, Pal SK, et al: S1PR1-STAT3 signaling is crucial for myeloid cell colonization at future metastatic sites. Cancer Cell 21: 642-654, 2012. 
54. Lin L, Liu A, Peng Z, Lin HJ, Li PK, Li C and Lin J: STAT3 is necessary for proliferation and survival in colon cancer-initiating cells. Cancer Res 71: 7226-7237, 2011.

55. Su YJ, Lai HM, Chang YW, Chen GY and Lee JL: Direct reprogramming of stem cell properties in colon cancer cells by CD44. EMBO J 30: 3186-3199, 2011.

56. Lee TK, Castilho A, Cheung VC, Tang KH, Ma S and Ng IO: $\mathrm{CD} 24(+)$ liver tumor-initiating cells drive self-renewal and tumor initiation through STAT3-mediated NANOG regulation. Cell Stem Cell 9: 50-63, 2011.

57. Won C, Kim BH, Yi EH, Choi KJ, Kim EK, Jeong JM, Lee JH, Jang JJ, Yoon JH, Jeong WI, et al: Signal transducer and activator of transcription 3-mediated CD133 upregulation contributes to promotion of hepatocellular carcinoma. Hepatology 62: $1160-1173,2015$

58. Niwa H, Ogawa K, Shimosato D and Adachi K: A parallel circuit of LIF signalling pathways maintains pluripotency of mouse ES cells. Nature 460: 118-122, 2009.

59. Marotta LL, Almendro V, Marusyk A, Shipitsin M, Schemme J, Walker SR, Bloushtain-Qimron N, Kim JJ, Choudhury SA Maruyama R, et al: The JAK2/STAT3 signaling pathway is required for growth of $\mathrm{CD} 44^{+} \mathrm{CD} 24^{-}$stem cell-like breast cancer cells in human tumors. J Clin Invest 121: 2723-2735, 2011.

60. Schroeder A, Herrmann A, Cherryholmes G, Kowolik C, Buettner R, Pal S, Yu H, Müller-Newen G and Jove R: Loss of androgen receptor expression promotes a stem-like cell phenotype in prostate cancer through STAT3 signaling. Cancer Res 74: 1227-1237, 2014.

61. Panni RZ, Sanford DE, Belt BA, Mitchem JB, Worley LA, Goetz BD, Mukherjee P, Wang-Gillam A, Link DC, Denardo DG, et al: Tumor-induced STAT3 activation in monocytic myeloidderived suppressor cells enhances stemness and mesenchymal properties in human pancreatic cancer. Cancer Immunol Immunother 63: 513-528, 2014

62. Wan S, Zhao E, Kryczek I, Vatan L, Sadovskaya A, Ludema G, Simeone DM, Zou W and Welling TH: Tumor-associated macrophages produce interleukin 6 and signal via STAT3 to promote expansion of human hepatocellular carcinoma stem cells. Gastroenterology 147: 1393-1404, 2014.

63. Kryczek I, Lin Y, Nagarsheth N, Peng D, Zhao L, Zhao E Vatan L, Szeliga W, Dou Y, Owens S, et al: IL-22(+)CD4(+) $\mathrm{T}$ cells promote colorectal cancer stemness via STAT3 transcription factor activation and induction of the methyltransferase DOT1L. Immunity 40: 772-784, 2014

64. Sano S, Itami S, Takeda K, Tarutani M, Yamaguchi Y, Miura H, Yoshikawa K, Akira S and Takeda J: Keratinocyte-specific ablation of Stat 3 exhibits impaired skin remodeling, but does not affect skin morphogenesis. EMBO J 18: 4657-4668, 1999.

65. Yamashita S, Miyagi C, Fukada T, Kagara N, Che YS and Hirano T: Zinc transporter LIVI controls epithelial-mesenchymal transition in zebrafish gastrula organizer. Nature 429: 298-302, 2004.

66. Huang C, Yang G, Jiang T, Zhu G, Li H and Qiu Z: The effects and mechanisms of blockage of STAT3 signaling pathway on IL-6 inducing EMT in human pancreatic cancer cells in vitro. Neoplasma 58: 396-405, 2011

67. Huang C, Yang G, Jiang T, Huang K, Cao J and Qiu Z: Effects of IL-6 and AG490 on regulation of Stat 3 signaling pathway and invasion of human pancreatic cancer cells in vitro. J Exp Clin Cancer Res 29: 51, 2010.

68. Liu H, Ren G, Wang T, Chen Y, Gong C, Bai Y, Wang B, Qi H, Shen J, Zhu L, et al: Aberrantly expressed Fra-1 by IL-6/STAT3 transactivation promotes colorectal cancer aggressiveness through epithelial-mesenchymal transition. Carcinogenesis 36 : $459-468,2015$

69. Tam WL, Lu H, Buikhuisen J, Soh BS, Lim E, Reinhardt F, Wu ZJ, Krall JA, Bierie B, Guo W, et al: Protein kinase C $\alpha$ is a central signaling node and therapeutic target for breast cancer stem cells. Cancer Cell 24: 347-364, 2013

70. Wang Y, Shi J, Chai K, Ying X and Zhou BP: The Role of Snail in EMT and Tumorigenesis. Curr Cancer Drug Targets 13: 963-972, 2013.

71. Ota I, Li XY, Hu Y and Weiss SJ: Induction of a MT1-MMP and MT2-MMP-dependent basement membrane transmigration program in cancer cells by Snaill. Proc Natl Acad Sci USA 106: 20318-20323, 2009.

72. Kudo-Saito C, Shirako H, Takeuchi T and Kawakami Y: Cancer metastasis is accelerated through immunosuppression during Snail-induced EMT of cancer cells. Cancer Cell 15: 195-206, 2009.
73. Hotz B, Arndt M, Dullat S, Bhargava S, Buhr HJ and Hotz HG: Epithelial to mesenchymal transition: Expression of the regulators snail, slug, and twist in pancreatic cancer. Clin Cancer Res 13: 4769-4776, 2007.

74. Shin NR, Jeong EH, Choi CI, Moon HJ, Kwon CH, Chu IS, Kim GH, Jeon TY, Kim DH, Lee JH, et al: Overexpression of Snail is associated with lymph node metastasis and poor prognosis in patients with gastric cancer. BMC Cancer 12: 521, 2012.

75. Kim YH, Kim G, Kwon CI, Kim JW, Park PW and Hahm KB TWIST1 and SNAI1 as markers of poor prognosis in human colorectal cancer are associated with the expression of ALDH1 and TGF-31. Oncol Rep 31: 1380-1388, 2014.

76. Yang MH, Chen CL, Chau GY, Chiou SH, Su CW, Chou TY, Peng WL and Wu JC: Comprehensive analysis of the independent effect of twist and snail in promoting metastasis of hepatocellular carcinoma. Hepatology 50: 1464-1474, 2009.

77. von Burstin J, Eser S, Paul MC, Seidler B, Brandl M, Messer M, von Werder A, Schmidt A, Mages J, Pagel P, et al: E-cadherin regulates metastasis of pancreatic cancer in vivo and is suppressed by a SNAIL/HDAC1/HDAC2 repressor complex. Gastroenterology 137: 361-371, 371.e1-5, 2009.

78. Herranz N, Pasini D, Díaz VM, Francí C, Gutierrez A, Dave N, Escrivà $\mathrm{M}$, Hernandez-Muñoz $\mathrm{I}$, Di Croce L, Helin $\mathrm{K}$, et al: Polycomb complex 2 is required for E-cadherin repression by the Snaill transcription factor. Mol Cell Biol 28: 4772-4781, 2008.

79. Chen J, Xu H, Zou X, Wang J, Zhu Y, Chen H, Shen B, Deng X, Zhou A, Chin YE, et al: Snail recruits Ring1B to mediate transcriptional repression and cell migration in pancreatic cancer cells. Cancer Res 74: 4353-4363, 2014

80. Vincent T, Neve EP, Johnson JR, Kukalev A, Rojo F, Albanell J, Pietras K, Virtanen I, Philipson L, Leopold PL, et al: A SNAIL1-SMAD3/4 transcriptional repressor complex promotes TGF-beta mediated epithelial-mesenchymal transition. Nat Cell Biol 11: 943-950, 2009.

81. Sahlgren C, Gustafsson MV, Jin S, Poellinger L and Lendahl U: Notch signaling mediates hypoxia-induced tumor cell migration and invasion. Proc Natl Acad Sci USA 105: 6392-6397, 2008

82. Yook JI, Li XY, Ota I, Hu C, Kim HS, Kim NH, Cha SY, Ryu JK, Choi YJ, Kim J, et al: A Wnt-Axin2-GSK3 $\beta$ cascade regulates Snaill activity in breast cancer cells. Nat Cell Biol 8: 1398-1406, 2006.

83. Wu Y, Deng J, Rychahou PG, Qiu S, Evers BM and Zhou BP. Stabilization of snail by NF-kappaB is required for inflammationinduced cell migration and invasion. Cancer Cell 15: 416-428, 2009.

84. Unno J, Satoh K, Hirota M, Kanno A, Hamada S, Ito H, Masamune A, Tsukamoto N, Motoi F, Egawa S, et al: LIV-1 enhances the aggressive phenotype through the induction of epithelial to mesenchymal transition in human pancreatic carcinoma cells. Int J Oncol 35: 813-821, 2009.

85. Shen R, Xie F and Shen H: liu Q, Zheng T, Kou X, Wang D and Yang J: Negative correlation of LIV-1 and E-cadherin expression in hepatocellular carcinoma cells. PLoS One 8: e56542, 2013

86. Hogstrand C, Kille P, Ackland ML, Hiscox S and Taylor KM: A mechanism for epithelial-mesenchymal transition and anoikis resistance in breast cancer triggered by zinc channel ZIP6 and STAT3 (signal transducer and activator of transcription 3). Biochem J 455: 229-237, 2013.

87. Yadav A, Kumar B, Datta J, Teknos TN and Kumar P: IL-6 promotes head and neck tumor metastasis by inducing epithelialmesenchymal transition via the JAK-STAT3-SNAIL signaling pathway. Mol Cancer Res 9: 1658-1667, 2011.

88. Saitoh M, Endo K, Furuya S, Minami M, Fukasawa A, Imamura T and Miyazawa K: STAT3 integrates cooperative Ras and TGF- $\beta$ signals that induce Snail expression. Oncogene 35: 1049-1057, 2016.

89. Lee DC, Kang YK, Kim WH, Jang YJ, Kim DJ, Park IY, Sohn BH, Sohn HA, Lee HG, Lim JS, et al: Functional and clinical evidence for NDRG2 as a candidate suppressor of liver cancer metastasis. Cancer Res 68: 4210-4220, 2008.

90. Kim MJ, Lim J, Yang Y, Lee MS and Lim JS: N-myc downstream-regulated gene 2 (NDRG2) suppresses the epithelial-mesenchymal transition (EMT) in breast cancer cells via STAT3/Snail signaling. Cancer Lett 354: 33-42, 2014.

91. Wang J, Yin D, Xie C, Zheng T, Liang Y, Hong X, Lu Z, Song X, Song R, Yang H, et al: The iron chelator Dp44mT inhibits hepatocellular carcinoma metastasis via N-Myc downstreamregulated gene 2 (NDRG2)/gp130/STAT3 pathway. Oncotarget 5: 8478-8491, 2014 
92. Yin X, Zhang BH, Zheng SS, Gao DM, Qiu SJ, Wu WZ and Ren ZG: Coexpression of gene Oct 4 and Nanog initiates stem cell characteristics in hepatocellular carcinoma and promotes epithelial-mesenchymal transition through activation of Stat3/Snail signaling. J Hematol Oncol 8: 23, 2015.

93. Yao C, Su L, Shan J, Zhu C, Liu L, Liu C, Xu Y, Yang Z, Bian X, Shao J, et al: IGF/STAT3/NANOG/Slug signaling axis simultaneously controls epithelial-mesenchymal transition and stemness maintenance in colorectal cancer. Stem Cells 34: 820-831, 2016.

94. Jung HY, Fattet L and Yang J: Molecular pathways: Linking tumor microenvironment to epithelial-mesenchymal transition in metastasis. Clin Cancer Res 21: 962-968, 2015.

95. Fu XT, Dai Z, Song K, Zhang ZJ, Zhou ZJ, Zhou SL, Zhao YM, Xiao YS, Sun QM, Ding ZB, et al: Macrophage-secreted IL-8 induces epithelial-mesenchymal transition in hepatocellular carcinoma cells by activating the JAK2/STAT3/Snail pathway. Int J Oncol 46: 587-596, 2015.

96. Hamada S, Masamune A, Yoshida N, Takikawa T and Shimosegawa T: IL-6/STAT3 plays a regulatory role in the interaction between pancreatic stellate cells and cancer cells. Dig Dis Sci 61: 1561-1571, 2016.

97. Kikuta K, Masamune A, Watanabe T, Ariga H, Itoh H, Hamada S, Satoh K, Egawa S, Unno M and Shimosegawa T: Pancreatic stellate cells promote epithelial-mesenchymal transition in pancreatic cancer cells. Biochem Biophys Res Commun 403: 380-384, 2010

98. Yang J, Mani SA, Donaher JL, Ramaswamy S, Itzykson RA, Come C, Savagner P, Gitelman I, Richardson A and Weinberg RA: Twist, a master regulator of morphogenesis, plays an essential role in tumor metastasis. Cell 117: 927-939, 2004

99. Sasaki K, Natsugoe S, Ishigami S, Matsumoto M, Okumura $H$ Setoyama T, Uchikado Y, Kita Y, Tamotsu K, Sakamoto A, et al: Significance of Twist expression and its association with E-cadherin in esophageal squamous cell carcinoma. J Exp Clin Cancer Res 28: 158, 2009.

100. Feng MY, Wang K, Song HT, Yu HW, Qin Y, Shi QT and Geng JS: Metastasis-induction and apoptosis-protection by TWIST in gastric cancer cells. Clin Exp Metastasis 26: 1013-1023, 2009.

101. Satoh K, Hamada S, Kimura K, Kanno A, Hirota M, Umino J, Fujibuchi W, Masamune A, Tanaka N, Miura K, et al: Upregulation of MSX2 enhances the malignant phenotype and is associated with twist 1 expression in human pancreatic cancer cells. Am J Pathol 172: 926-939, 2008.

102. Tsai JH, Donaher JL, Murphy DA, Chau S and Yang J: Spatiotemporal regulation of epithelial-mesenchymal transition is essential for squamous cell carcinoma metastasis. Cancer Cell 22: 725-736, 2012

103. Yang MH, Wu MZ, Chiou SH, Chen PM, Chang SY, Liu CJ, Teng SC and Wu KJ: Direct regulation of TWIST by HIF-1 $\alpha$ promotes metastasis. Nat Cell Biol 10: 295-305, 2008.

104. Hong J, Zhou J, Fu J, He T, Qin J, Wang L, Liao L and Xu J: Phosphorylation of serine 68 of Twist 1 by MAPKs stabilizes Twist1 protein and promotes breast cancer cell invasiveness. Cancer Res 71: 3980-3990, 2011.

105. Xue G, Restuccia DF, Lan Q, Hynx D, Dirnhofer S, Hess D, Rüegg C and Hemmings BA: Akt/PKB-mediated phosphorylation of Twist1 promotes tumor metastasis via mediating cross-talk between PI3K/Akt and TGF- $\beta$ signaling axes. Cancer Discov 2: 248-259, 2012

106. Fu J, Qin L, He T, Qin J, Hong J, Wong J, Liao L and Xu J: The TWIST/Mi2/NuRD protein complex and its essential role in cancer metastasis. Cell Res 21: 275-289, 2011.

107. Yang MH, Hsu DS, Wang HW, Wang HJ, Lan HY, Yang WH, Huang $\mathrm{CH}$, Kao SY, Tzeng CH, Tai SK, et al: Bmil is essential in Twist1-induced epithelial-mesenchymal transition. Nat Cell Biol 12: 982-992, 2010.

108. Cheng GZ, Zhang WZ, Sun M, Wang Q, Coppola D, Mansour M, Xu LM, Costanzo C, Cheng JQ and Wang LH: Twist is transcriptionally induced by activation of STAT3 and mediates STAT3 oncogenic function. J Biol Chem 283: 14665-14673, 2008.

109. Sullivan NJ, Sasser AK, Axel AE, Vesuna F, Raman V, Ramirez N, Oberyszyn TM and Hall BM: Interleukin-6 induces an epithelial-mesenchymal transition phenotype in human breast cancer cells. Oncogene 28: 2940-2947, 2009.

110. Zhang C, Guo F, Xu G, Ma J and Shao F: STAT3 cooperates with Twist to mediate epithelial-mesenchymal transition in human hepatocellular carcinoma cells. Oncol Rep 33: 1872-1882, 2015.

111. Cho KH, Choi MJ, Jeong KJ, Kim JJ, Hwang MH, Shin SC, Park CG and Lee HY: A ROS/STAT3/HIF- $1 \alpha$ signaling cascade mediates EGF-induced TWIST1 expression and prostate cancer cell invasion. Prostate 74: 528-536, 2014.
112. Lo HW, Hsu SC, Xia W, Cao X, Shih JY, Wei Y, Abbruzzese JL, Hortobagyi GN and Hung MC: Epidermal growth factor receptor cooperates with signal transducer and activator of transcription 3 to induce epithelial-mesenchymal transition in cancer cells via upregulation of TWIST gene expression. Cancer Res 67: 9066-9076, 2007.

113. Zhang P, Sun Y and Ma L: ZEB1: At the crossroads of epithelialmesenchymal transition, metastasis and therapy resistance. Cell Cycle 14: 481-487, 2015.

114. Shi Y, Sawada J, Sui G, Affar B, Whetstine JR, Lan F, Ogawa H, Luke MP, Nakatani Y and Shi Y: Coordinated histone modifications mediated by a CtBP co-repressor complex. Nature 422 : 735-738, 2003

115. Sánchez-Tilló E, Lázaro A, Torrent R, Cuatrecasas M, Vaquero EC, Castells A, Engel P and Postigo A: ZEB1 represses E-cadherin and induces an EMT by recruiting the SWI/SNF chromatinremodeling protein BRG1. Oncogene 29: 3490-3500, 2010.

116. Aghdassi A, Sendler M, Guenther A, Mayerle J, Behn CO, Heidecke CD, Friess H, Büchler M, Evert M, Lerch MM, et al: Recruitment of histone deacetylases HDAC1 and HDAC2 by the transcriptional repressor ZEB1 downregulates E-cadherin expression in pancreatic cancer. Gut 61: 439-448, 2012.

117. Dave N, Guaita-Esteruelas S, Gutarra S, Frias À, Beltran M,Peiró S and de Herreros AG: Functional cooperation between Snaill and twist in the regulation of ZEB1 expression during epithelial to mesenchymal transition. J Biol Chem 286: 12024-12032, 2011.

118. Gregory PA, Bert AG, Paterson EL, Barry SC, Tsykin A, Farshid G, Vadas MA, Khew-Goodall Y and Goodall GJ: The miR-200 family and miR-205 regulate epithelial to mesenchymal transition by targeting ZEB1 and SIP1. Nat Cell Biol 10: 593-601, 2008.

119. Burk U, Schubert J, Wellner U, Schmalhofer O, Vincan E, Spaderna $\mathrm{S}$ and Brabletz T: A reciprocal repression between ZEB1 and members of the miR-200 family promotes EMT and invasion in cancer cells. EMBO Rep 9: 582-589, 2008.

120. Wellner U, Schubert J, Burk UC, Schmalhofer O, Zhu F, Sonntag A, Waldvogel B, Vannier C, Darling D, zur Hausen A, et al: The EMT-activator ZEB1 promotes tumorigenicity by repressing stemness-inhibiting microRNAs. Nat Cell Biol 11: $1487-1495,2009$.

121. Xiong H, Hong J, Du W, Lin YW, Ren LL, Wang YC, Su WY, Wang JL, Cui Y, Wang ZH, et al: Roles of STAT3 and ZEB1 proteins in E-cadherin downregulation and human colorectal cancer epithelial-mesenchymal transition. J Biol Chem 287: 5819-5832, 2012.

122. Avtanski DB, Nagalingam A, Bonner MY, Arbiser JL, Saxena NK and Sharma D: Honokiol inhibits epithelialmesenchymal transition in breast cancer cells by targeting signal transducer and activator of transcription 3/Zeb1/E-cadherin axis. Mol Oncol 8: 565-580, 2014.

123. Bak Y, Kwon T, Bak IS, Hong J, Yu DY and Yoon DY: IL-320 inhibits stemness and epithelial-mesenchymal transition of cancer stem cells via the STAT3 pathway in colon cancer. Oncotarget 7: 7307-7317, 2016

124. Tsai CY, Wang CS, Tsai MM, Chi HC, Cheng WL, Tseng YH, Chen CY, Lin CD, Wu JI, Wang LH, et al: Interleukin-32 increases human gastric cancer cell invasion associated with tumor progression and metastasis. Clin Cancer Res 20: 2276-2288, 2014.

125. Cao Q, Li YY, He WF, Zhang ZZ, Zhou Q, Liu X, Shen Y and Huang TT: Interplay between microRNAs and the STAT3 signaling pathway in human cancers. Physiol Genomics 45: 1206-1214, 2013.

126. Siemens H, Jackstadt R, Hünten S, Kaller M, Menssen A, Götz U and Hermeking H: miR-34 and SNAIL form a double-negative feedback loop to regulate epithelial-mesenchymal transitions. Cell Cycle 10: 4256-4271, 2011.

127. Chang CJ, Chao CH, Xia W, Yang JY, Xiong Y, Li CW, Yu WH, Rehman SK, Hsu JL, Lee HH, et al: p53 regulates epithelialmesenchymal transition and stem cell properties through modulating miRNAs. Nat Cell Biol 13: 317-323, 2011

128. Kim NH, Kim HS, Li XY, Lee I, Choi HS, Kang SE, Cha SY, Ryu JK, Yoon D, Fearon ER, et al: A p53/miRNA-34 axis regulates Snaill-dependent cancer cell epithelial-mesenchymal transition. J Cell Biol 195: 417-433, 2011.

129. Rokavec M, Öner MG, Li H, Jackstadt R, Jiang L, Lodygin D, Kaller M, Horst D, Ziegler PK, Schwitalla S, et al: IL-6R/STAT3/ miR-34a feedback loop promotes EMT-mediated colorectal cancer invasion and metastasis. J Clin Invest 124: 1853-1867, 2014. 
130. Guo L, Chen C, Shi M, Wang F, Chen X, Diao D, Hu M, Yu M, Qian L and Guo N: Stat3-coordinated Lin-28-let-7-HMGA2 and miR-200-ZEB1 circuits initiate and maintain oncostatin M-driven epithelial-mesenchymal transition. Oncogene 32: 5272-5282, 2013.

131.Patel K, Kollory A, Takashima A, Sarkar S, Faller DV and Ghosh SK: MicroRNA let-7 downregulates STAT3 phosphorylation in pancreatic cancer cells by increasing SOCS3 expression. Cancer Lett 347: 54-64, 2014.

132. Sugimura K, Miyata H, Tanaka K, Hamano R, Takahashi T, Kurokawa Y, Yamasaki M, Nakajima K, Takiguchi S, Mori M, et al: Let-7 expression is a significant determinant of response to chemotherapy through the regulation of IL-6/STAT3 pathway in esophageal squamous cell carcinoma. Clin Cancer Res 18: 5144-5153, 2012.

133.Li Y, VandenBoom TG II, Kong D, Wang Z, Ali S, Philip PA and Sarkar FH: Upregulation of miR-200 and let-7 by natural agents leads to the reversal of epithelial-to-mesenchymal transition in gemcitabine-resistant pancreatic cancer cells. Cancer Res 69: 6704-6712, 2009.

134. Nagao Y, Hisaoka M, Matsuyama A, Kanemitsu S, Hamada T, Fukuyama T, Nakano R, Uchiyama A, Kawamoto M, Yamaguchi K, et al: Association of microRNA-21 expression with its targets, PDCD4 and TIMP3, in pancreatic ductal adenocarcinoma. Mod Pathol 25: 112-121, 2012.

135. Selaru FM, Olaru AV, Kan T, David S, Cheng Y, Mori Y, Yang J, Paun B, Jin Z, Agarwal R, et al: MicroRNA-21 is overexpressed in human cholangiocarcinoma and regulates programmed cell death 4 and tissue inhibitor of metalloproteinase 3 . Hepatology 49: 1595-1601, 2009.

136.Löffler D, Brocke-Heidrich K, Pfeifer G, Stocsits C, Hackermüller J, Kretzschmar AK, Burger R, Gramatzki M, Blumert C, Bauer K, et al: Interleukin- 6 dependent survival of multiple myeloma cells involves the Stat3-mediated induction of microRNA-21 through a highly conserved enhancer. Blood 110: $1330-1333,2007$.

137. Yue X, Zhao Y, Zhang C, Li J, Liu Z, Liu J and Hu W: Leukemia inhibitory factor promotes EMT through STAT3-dependent miR-21 induction. Oncotarget 7: 3777-3790, 2016

138. Luo F, Xu Y, Ling M, Zhao Y, Xu W, Liang X, Jiang R, Wang B, Bian Q and Liu Q: Arsenite evokes IL-6 secretion, autocrine regulation of STAT3 signaling, and miR-21 expression, processes involved in the EMT and malignant transformation of human bronchial epithelial cells. Toxicol Appl Pharmacol 273: $27-34,2013$.

139. Gironella M, Seux M, Xie MJ, Cano C, Tomasini R, Gommeaux J, Garcia S, Nowak J, Yeung ML, Jeang KT, et al: Tumor protein 53 -induced nuclear protein 1 expression is repressed by miR-155, and its restoration inhibits pancreatic tumor development. Proc Natl Acad Sci USA 104: 16170-16175, 2007.

140. Huang C, Li H, Wu W, Jiang T and Qiu Z: Regulation of miR-155 affects pancreatic cancer cell invasiveness and migration by modulating the STAT3 signaling pathway through SOCS1. Oncol Rep 30: 1223-1230, 2013.

141. Jiang S, Zhang HW, Lu MH, He XH, Li Y, Gu H, Liu MF and Wang ED: MicroRNA-155 functions as an OncomiR in breast cancer by targeting the suppressor of cytokine signaling 1 gene. Cancer Res 70: 3119-3127, 2010

142. Yuan JH, Yang F, Wang F, Ma JZ, Guo YJ, Tao QF, Liu F, Pan W, Wang TT, Zhou CC, et al: A long noncoding RNA activated by TGF- $\beta$ promotes the invasion-metastasis cascade in hepatocellular carcinoma. Cancer Cell 25: 666-681, 2014.

143. Wu J, Zhang J, Shen B, Yin K, Xu J, Gao W and Zhang L: Long noncoding RNA lncTCF7, induced by IL-6/STAT3 transactivation, promotes hepatocellular carcinoma aggressiveness through epithelial-mesenchymal transition. J Exp Clin Cancer Res 34: 116, 2015

144. Qu S, Yang X, Li X, Wang J, Gao Y, Shang R, Sun W, Dou K and Li H: Circular RNA: A new star of noncoding RNAs. Cancer Lett 365: 141-148, 2015.

145. Hansen TB, Jensen TI, Clausen BH, Bramsen JB, Finsen B, Damgaard CK and Kjems J: Natural RNA circles function as efficient microRNA sponges. Nature 495: 384-388, 2013.
146. Zhao X, Dou W, He L, Liang S, Tie J, Liu C, Li T, Lu Y, Mo P, Shi Y, et al: MicroRNA-7 functions as an anti-metastatic microRNA in gastric cancer by targeting insulin-like growth factor-1 receptor. Oncogene 32: 1363-1372, 2013.

147. Zhang N, Li X, Wu CW, Dong Y, Cai M, Mok MT, Wang H, Chen J, Ng SS, Chen M, et al: microRNA-7 is a novel inhibitor of YY1 contributing to colorectal tumorigenesis. Oncogene 32: 5078-5088, 2013.

148. Xie H, Ren X, Xin S, Lan X, Lu G, Lin Y, Yang S, Zeng Z, Liao W, Ding YQ, et al: Emerging roles of circRNA 001569 targeting miR-145 in the proliferation and invasion of colorectal cancer. Oncotarget 7: 26680-26691, 2016.

149. Massagué J: TGFbeta in cancer. Cell 134: 215-230, 2008

150. Zhao S, Venkatasubbarao K, Lazor JW, Sperry J, Jin C, Cao L and Freeman JW: Inhibition of STAT3 Tyr705 phosphorylation by Smad4 suppresses transforming growth factor beta-mediated invasion and metastasis in pancreatic cancer cells. Cancer Res 68: 4221-4228, 2008

151. Liu RY, Zeng Y, Lei Z, Wang L, Yang H, Liu Z, Zhao J and Zhang HT: JAK/STAT3 signaling is required for TGF- $\beta$-induced epithelial-mesenchymal transition in lung cancer cells. Int J Oncol 44: 1643-1651, 2014

152. Espinoza I and Miele L: Deadly crosstalk: Notch signaling at the intersection of EMT and cancer stem cells. Cancer Lett 341: 41-45, 2013

153. Wang Z, Li Y, Kong D, Banerjee S, Ahmad A, Azmi AS, Ali S, Abbruzzese JL, Gallick GE and Sarkar FH: Acquisition of epithelial-mesenchymal transition phenotype of gemcitabineresistant pancreatic cancer cells is linked with activation of the notch signaling pathway. Cancer Res 69: 2400-2407, 2009.

154. Palagani V, Bozko P, El Khatib M, Belahmer H, Giese N, Sipos B, Malek NP and Plentz RR: Combined inhibition of Notch and JAK/STAT is superior to monotherapies and impairs pancreatic cancer progression. Carcinogenesis 35: 859-866, 2014.

155. Hsu KW, Hsieh RH, Huang KH, Fen-Yau Li A, Chi CW, Wang TY, Tseng MJ, Wu KJ and Yeh TS: Activation of the Notch1/STAT3/Twist signaling axis promotes gastric cancer progression. Carcinogenesis 33: 1459-1467, 2012.

156. Kamakura S, Oishi K, Yoshimatsu T, Nakafuku M, Masuyama N and Gotoh Y: Hes binding to STAT3 mediates crosstalk between Notch and JAK-STAT signalling. Nat Cell Biol 6: 547-554, 2004.

157. Jin S, Mutvei AP, Chivukula IV, Andersson ER, Ramsköld D, Sandberg R, Lee KL, Kronqvist P, Mamaeva V, Ostling P, et al: Non-canonical Notch signaling activates IL-6/JAK/STAT signaling in breast tumor cells and is controlled by p53 and IKK $\alpha /$ IKK $\beta$. Oncogene 32: 4892-4902, 2013.

158. Yang Z, Guo L, Liu D, Sun L, Chen H, Deng Q, Liu Y, Yu M, Ma Y, Guo N, et al: Acquisition of resistance to trastuzumab in gastric cancer cells is associated with activation of IL-6/STAT3/Jagged-1/Notch positive feedback loop. Oncotarget 6: 5072-5087, 2015.

159. Kawada M, Seno H, Uenoyama Y, Sawabu T, Kanda N, Fukui H, Shimahara Y and Chiba T: Signal transducers and activators of transcription 3 activation is involved in nuclear accumulation of beta-catenin in colorectal cancer. Cancer Res 66: 2913-2917, 2006.

160. Pramanik KC, Fofaria NM, Gupta P, Ranjan A, Kim SH and Srivastava SK: Inhibition of $\beta$-catenin signaling suppresses pancreatic tumor growth by disrupting nuclear $\beta$-catenin/TCF-1 complex: Critical role of STAT-3. Oncotarget 6: 11561-11574, 2015.

161. Yan S, Zhou C, Zhang W, Zhang G, Zhao X, Yang S, Wang Y, $\mathrm{Lu} \mathrm{N}$, Zhu $\mathrm{H}$ and $\mathrm{Xu}$ N: beta-Catenin/TCF pathway upregulates STAT3 expression in human esophageal squamous cell carcinoma. Cancer Lett 271: 85-97, 2008.

162. Gujral TS, Chan M, Peshkin L, Sorger PK, Kirschner MW and MacBeath G: A noncanonical Frizzled2 pathway regulates epithelial-mesenchymal transition and metastasis. Cell 159: 844-856, 2014. 